\title{
Mediterranean Sea Hydrographic Atlas: towards optimal data analysis by including time-dependent statistical parameters
}

\author{
Athanasia Iona ${ }^{1,2}$, Athanasios Theodorou ${ }^{2},{\text { Sylvain } \text { Watelet }^{3}, \text { Charles Troupin }^{3} \text {, Jean-Marie Beckers }}^{3}$, \\ and Simona Simoncelli ${ }^{4}$ \\ ${ }^{1}$ Hellenic Centre for Marine Research, Institute of Oceanography, Hellenic National Oceanographic Data \\ Centre, 46,7 km Athens Sounio, Mavro Lithari P.O. Box 71219013 Anavissos, Attica, Greece \\ ${ }^{2}$ University of Thessaly, Department of Ichthyology \& Aquatic Environment, \\ Laboratory of Oceanography, Fytoko Street, 38 445, Nea Ionia Magnesia, Greece \\ ${ }^{3}$ University of Liège, GeoHydrodynamics and Environment Research, Quartier Agora, \\ Allée du 6-Août, 17, Sart Tilman, 4000 Liège 1, Belgium \\ ${ }^{4}$ Istituto Nazionale di Geofisica e Vulcanologia (INGV), Sezione di Bologna, \\ Via Franceschini 31, 40128 Bologna, Italy \\ Correspondence: Athanasia Iona (sissy@hnodc.hcmr.gr)
}

Received: 30 January 2018 - Discussion started: 2 February 2018

Revised: 13 April 2018 - Accepted: 16 April 2018 - Published: 16 July 2018

\begin{abstract}
The goal of the present work is to provide the scientific community with a high-resolution atlas of temperature and salinity for the Mediterranean Sea based on the most recent datasets available and contribute to the studies of the long-term variability in the region. Data from the pan-European marine data infrastructure SeaDataNet were used, the most complete and, to our best knowledge, best quality dataset for the Mediterranean Sea as of today. The dataset is based on in situ measurements acquired between 1900 and 2015. The atlas consists of horizontal gridded fields produced by the Data-Interpolating Variational Analysis, in which unevenly spatial distributed measurements were interpolated onto a $1 / 8^{\circ} \times 1 / 8^{\circ}$ regular grid on 31 depth levels. Seven different types of climatological fields were prepared with different temporal integration of observations. Monthly, seasonal and annual climatological fields have been calculated for all the available years, seasonal to annual climatologies for overlapping decades and specific periods. The seasonal and decadal time frames have been chosen in accordance with the regional variability and in coherence with atmospheric indices. The decadal and specificperiod analysis was not extended to monthly resolution due to the lack of data, especially for the salinity. The Data-Interpolating Variational Analysis software has been used in the Mediterranean region for the SeaDataNet and its predecessor Medar/Medatlas Climatologies. In the present study, a more advanced optimization of the analysis parameters was performed in order to produce more detailed results. The past and present states of the Mediterranean region have been extensively studied and documented in a series of publications. The purpose of this atlas is to contribute to these climatological studies and get a better understanding of the variability on timescales from months to decades and longer. Our gridded fields provide a valuable complementary source of knowledge in regions where measurements are scarce, especially in critical areas of interest such as the Marine Strategy Framework Directive (MSFD) regions and subregions. The dataset used for the preparation of the atlas is available from https://doi.org/10.12770/8c3bd19b-9687-429c-a232-48b10478581c.

The climatologies in netCDF are available at the following sources: annual climatology (https://doi.org/10.5281/zenodo.1146976), seasonal climatology for 57 running decades (https://doi.org/10.5281/zenodo.1146938), seasonal climatology (https://doi.org/10.5281/zenodo.1146953), annual climatology for 57 running decades (https://doi.org/10.5281/zenodo.1146957), seasonal climatology for six periods (https://doi.org/10.5281/zenodo.1146966), annual climatology for six periods (https://doi.org/10.5281/zenodo.1146970), monthly climatology (https://doi.org/10.5281/zenodo.1146974).
\end{abstract}




\section{Introduction}

In oceanography, a climatology is defined as a set of gridded fields that describe the mean state of the ocean properties over a given time period. It is constructed by the analysis of in situ historical data sets and has many applications such as initialization of numerical models and quality control of observational data in real time and delayed mode, and it is used as a baseline for comparison to understand how the ocean is changing. The Mediterranean Sea is among the most interesting regions in the world because it influences the global thermohaline circulation and plays an important role in regulating the global climate (Lozier et al., 1995; Béthoux et al., 1998; Rahmstorf, 1998). It is therefore essential to improve our understanding of its dynamics and its process variability. It is a semi-enclosed sea divided by the Sicily Strait in two geographical basins, the western Mediterranean and the eastern Mediterranean, and is characterized by peculiar topographic deep depressions where nutrient-rich deep-water masses are stored for long time (Manca et al., 2004). It is a concentration basin, where evaporation exceeds precipitation. The general mean circulation pattern is driven by the continuous evaporation, heat flux exchanges with the atmosphere, the wind stress and the water mass exchanges between its basins and subbasins, as described in Robinson et al. (2001). In the surface layer $(0-150 \mathrm{~m})$ there is an inflow of warm and relatively fresh Atlantic water (AW; $S \approx 36.5 \mathrm{ppt}, T \approx 15^{\circ} \mathrm{C}$ ) which is modified along its path to the eastern basin following a general cyclonic circulation. The intermediate layers $(150-600 \mathrm{~m})$ are dominated by the saline Levantine Intermediate Water (LIW; $S \approx 38.4 \mathrm{ppt}$, $T \approx 13.5^{\circ} \mathrm{C}$ ), regularly formed at the Levantine basin. LIW is one of the most important Mediterranean water masses because it constitutes the higher percentage of the outflow from the Gibraltar Strait towards the Atlantic Ocean. In the deep layers, there are two main thermohaline cells. Deep waters formed via convective events in the northern regions of the western Mediterranean (WMDW - Western Mediterranean Deep Water; $S \approx 38.44-38.46 \mathrm{ppt}, T \approx 12.75-13.80^{\circ} \mathrm{C}$ ) in the Gulf of Lion and in the northern regions of the eastern Mediterranean (EMDW - Eastern Mediterranean Deep Waters) in the Adriatic $\left(S \approx 38.65 \mathrm{ppt}, T \approx 13.0^{\circ} \mathrm{C}\right)$ and Cre$\tan$ seas $\left(S \approx 39 \mathrm{ppt}, T \approx 14.8^{\circ} \mathrm{C}\right)$. On top of this largescale general pattern are superimposed several subbasinscale and mesoscale cyclonic and anticyclonic motions due to topographic constraints and internal processes. The first climatological studies of the Mediterranean go back to 1966 with Ovchinnikov who carried out a geostrophic analysis to compute the surface circulation. The circulation features were describing a linear, stationary ocean. In the 1980s and 1990s, through a comprehensive series of observational studies and experiments in the western Mediterranean (La Violette, 1990; Millot, 1987, 1991, 1999), the subbasin and mesoscale patterns were discovered and the crucial role of eddies in modifying the mean climatological circulation and mixing properties inside the different subbasins which include the Tyrrhenian, Ligurian, and Alboran seas was emphasized (Bergamasco and Malanotte-Rizzoli, 2010). In 1987, Guibout constructed charts with the typical structures observed at sea, but with limited climatological characteristic as this atlas was based on the quasi-synoptic information of the selected cruise used. In 1982, an international research group was formed, called POEM (Physical Oceanography of the Eastern Mediterranean, 1984), under the auspices of the IOC/UNESCO and of CIESM (Commission Internationale pour l'Exploration Scientifique de la Méditerranée), which is focused on the description of the phenomenology of the eastern Mediterranean, by analyzing historical data and collecting new data (Malanotte-Rizzoli and Hecht, 1988). However, the focus was on the eastern Mediterranean Sea, as there was very little knowledge of this basin compared to the western Mediterranean and other world regions, and still there was no global data set to describe the eastern Mediterranean and its interaction with the western part efficiently. It is worth noting here that it was the POEM cruises that provided the observational evidence of the profound changes in the eastern Mediterranean deep circulation between the late 1980s and mid-1990s. During this phenomenon, known as Eastern Mediterranean Transient (EMT) the deep water production in the eastern Mediterranean shifted from the Adriatic to the Aegean. The bottom layers of the eastern Mediterranean were replaced by waters warmer but also much saltier and hence denser than the previous Eastern Mediterranean Deep Waters (Malanotte-Rizzoli et al., 1999; Lascaratos et al., 1999; Klein et al., 1999; Roether et al., 1996). The EMT affected not only the thermohaline characteristics of intermediate and deep water masses of eastern Mediterranean but also the western Mediterranean deep water production (Schröder et al., 2006; Schroeder et al., 2016). The EMT "signature" can be captured to the climatological references of a region and can be used to improve the near-real-time control procedures of operational and delayed mode data (Manzella et al., 2013). Hecht et al. (1988), by analyzing hydrographic measurements in the southeastern Levantine Basin, succeeded in describing the climatological water masses of the region and identifying their seasonal variations. In the western Mediterranean, Picco (1990) conducted an important climatological study and constructed a climatological atlas analyzing around 15000 hydrological profiles from various sources for the period 1909-1987. In 1982, Levitus published the first climatological atlas of the world ocean at a $1^{\circ}$ resolution, using temperature, salinity, and oxygen data from CTD, bottle stations, mechanical, and expendable bathythermographs of the previous 80 years. An objective analysis at standard levels was carried out to compute the climatology. Since 1994 , a new version is released every 4 years. The current 
version that includes the Mediterranean (World Ocean Atlas 2013, V2; Locarnini et al., 2013) is a long-term set of objectively analyzed climatologies of temperature, salinity, oxygen, phosphate, silicate, and nitrate for annual, seasonal, and monthly periods for the world ocean. It also includes associated statistical fields of observed oceanographic profile data from which the climatologies were computed. In addition to increased vertical resolution, the 2013 version has both 1 and $1 / 4^{\circ}$ horizontal resolution versions available for annual and seasonal temperature and salinity for 6 decades, as well as monthly for the decadal average. Brasseur et al. (1996) introduced a new method to reconstruct the threedimensional fields of the properties of the Mediterranean Sea. Seasonal and monthly fields were analyzed using a variational inverse method (VIM) to generate the climatological maps, instead of the objective analysis introduced by Gandin (1966) and Bretherton et al. (1976) on the meteorology and oceanography which was widely used by then. More than 34000 CTD and bottle data were used and integrated in the so-called MED2 historical database. Comparison of the results obtained with both methods showed that VIM was mathematically equivalent but numerically more efficient than the objective analysis. The method has been adopted by the Medar/Medatlas and its successor SeaDataNet Project.

At the beginning of the 2000s, many research projects and monitoring activities have produced large amounts of multidisciplinary in situ hydrographic and biochemical data for the whole Mediterranean Sea, but still the data were fragmented and inaccessible from the scientific community. The aim of the EU/MAST Medar/Medatlas Project, 2001 (http://www.ifremer.fr/medar/, last access: 9 July 2018) was to rescue and archive the dispersed data through a wide cooperation of countries and produce an atlas for 12 core parameters: temperature and salinity, dissolved oxygen, hydrogen sulfur, alkalinity, phosphate, ammonium, nitrite, nitrate, silicate, chlorophyll and $\mathrm{pH}$. Gridded fields have been computed on a $1 / 4^{\circ}$ grid resolution using the VIM and the DIVA tool developed by the GHER group of the University of Liège. Interannual and decadal variabilities of temperature and salinity were computed as well. The atlas is available at http://modb.oce.ulg.ac.be/backup/medar/ contribution.html (last access: 9 July 2018) and on CD-Rom (MEDAR Group, 2002). The atlas contains a selection of figures and three-dimensional fields in netCDF. The EU FP7 SeaDataNet project, 2006-2011 and 2012-2016 (the successor of the EU/MAST Medar/Medatlas), has integrated historical, multidisciplinary data on a unique, standardized online data management infrastructure and provides valueadded aggregated datasets and regional climatologies based on these aggregated datasets for all the European sea basins. SeaDataNet has adopted the VIM method and the DIVA software tool. Temperature and salinity monthly climatologies have been produced on a $1 / 8^{\circ}$ grid resolution (Simoncelli et al., 2015a, 2016, https://doi.org/10.12770/90ae7a06-8b08- 4afe-83dd-ca92bc99f5c0). These climatologies are based on the V1.1 historical data collection of publicly available temperature and salinity in situ profiles (Simoncelli et al., 2014, https://doi.org/10.12770/90ae7a06-8b08-4afe83dd-ca92bc99f5c0) spanning the time period 1900-2013 (Simoncelli et al., 2015a).

\subsection{Objectives}

The objective of this study is the computation of an improved atlas compared with the existing products in the Mediterranean Sea using the latest developments of the DIVA tool with the aim to contribute to the better representation of the climatological patterns and understanding of the long-term variability of the regional features of the basin. The originality of this product compared to the SeaDataNet climatology (both products use similar techniques) is the higher temporal resolution, up to decadal, and more advanced calibration of the analysis parameters for improving the results and the representation of general circulation patterns at timescales smaller than the climatic means. Besides the WOA13 decadal periods climatologies (1955-1964, 19651974, 1975-1984, 1985-1994, 1995-2004, and 2005-2012) the Medar/Medatlas provides interannual and decadal gridded fields and therefore it is compared with the present atlas. The present product has two major improvements: higher spatial and vertical resolutions and error fields that accompany all the analysis results, therefore allowing a more reliable assessment of the results. The advantage of this product in relation to the WOA13 climatology is the higher spatial resolution (up to $1 / 8^{\circ} \times 1 / 8^{\circ}$ ) longitude-latitude grids used and the higher temporal resolution as the analysis uses running decades instead of successive decades. Another important difference with respect to all previous existing climatologies in the Mediterranean is that additional and more recent data are used. The atlas constructed consists of climatological fields (called climatology hereafter) to depict the "mean" state of the Mediterranean region at monthly, seasonal (winter: January-March; spring: April-June; summer: July-September; fall: October-December), and annual scale. Additionally, climatological fields at seasonal and annual scale for 57 running decades have been produced to depict the interannual and decadal variability of the system and reveal the decadal trends.

One additional period from 2000-2015 was produced for those users or applications who are interested to reference to the latest data and new platform types such as Argo floats. This period is provided with the five previous successive decadal periods, e.g., 1950-1959, 1960-1969, 1970-1979, 1980-1989, 1990-1999, and 2000-2015. In summary, the following gridded products are available:

- monthly climatological gridded fields obtained by analyzing all monthly data of the whole period 1950 to 2015; 
- seasonal climatological gridded fields obtained by analyzing all monthly data of the whole period from 1950 to 2015 falling within each season;

- seasonal gridded fields obtained by analyzing all data falling within each season for each of 57 seasons over the running decades from 1950-1959 to 2006-2015;

- seasonal gridded fields obtained by analyzing data falling within each season for six periods: 19501959, 1960-1969, 1970-1979, 1980-1989, 1990-1999, 2000-2015;

- annual climatology obtained by analyzing all data (regardless month or season) for the whole period from 1950 to 2015;

- annual gridded fields obtained by analyzing all data regardless month or season for each of the 57 seasons over the running decades from 1950-1959 to 2006-2015;

- annual gridded fields obtained by analyzing data falling with each season for six periods, 1950-1959, 19601969, 1970-1979, 1980-1989-1990-1999, 2000-2015. The first five periods coincide with the corresponding decades.

The climatologies provided cannot rely on sufficient highfrequency and high-resolution data to allow mesoscale features, which play an important role and modify the largescale flow fields, to be resolved (Robinson et al., 2001). We focus thus on the seasonal and decadal variations. This time filtering also results in a spatial filter as later shown by the spatial correlations found in the data. The spatial scales the data can capture are of the order of $300-350 \mathrm{~km}$ at the surface, much larger than the Rossby radius of deformation scale $(10-15 \mathrm{~km})$ associated with mesoscale motions (30$80 \mathrm{~km}$, Robinson et al., 2001). These mesoscale features are thus filtered out from the analysis and hence the numerical grids we will use only need to resolve the large scales. The same holds for the output files, where there is no reason to save at very high resolution (much smaller than the deformation radius) as in any case the analysis provides large-scale fields.

The atlas covers the geographical region $30-46^{\circ} \mathrm{N}$, $6.25^{\circ} \mathrm{W}-36.5^{\circ} \mathrm{E}$ on 31 standard depth levels from 0 to $4000 \mathrm{~m}$. The fields are stored in netCDF files. The atlas is accessible in netCDF from the Zenodo platform using the following DOIs: annual climatology (https://doi.org/10.5281/zenodo.1146976), seasonal climatology for 57 running decades from 1950-1959 to 20062015 (https://doi.org/10.5281/zenodo.1146938); seasonal climatology (https://doi.org/10.5281/zenodo.1146953), annual climatology for 57 running decades from 1950-1959 to 2006-2015 (https://doi.org/10.5281/zenodo.1146957); seasonal climatology for six periods: 1950-1959, 1960-1969, 1970-1979, 1980-1989, 1990-1999,
2000-2015 (https://doi.org/10.5281/zenodo.1146966); annual climatology for six periods: 1950-1959, 19601969, 1970-1979, 1980-1989, 1990-1999, 2000-2015 (https://doi.org/10.5281/zenodo.1146970); monthly climatology (https://doi.org/10.5281/zenodo.1146974).

Tables 1 and 2 give the state of the art of the existing climatologies in the Mediterranean Sea.

\section{Data}

\subsection{Data source}

The SeaDataNet historical temperature and salinity data collection V2 for the Mediterranean Sea was used (Simoncelli et al., 2015b, http://sextant.ifremer.fr/record/ 8c3bd19b-9687-429c-a232-48b10478581c/, last access: 9 July 2018). The collection includes 213542 temperature and 138691 salinity profiles from in situ measurements covering the 1911-2015 period, which corresponds to all openaccess data available through the European SeaDataNet Marine Data Infrastructure (www.seadatanet.org, last access: 9 July 2018). These datasets were collected from 102 data providers, are quality controlled and archived in 32 marine and oceanographic data centers, and distributed into the infrastructure by $27 \mathrm{SeaDataNet}$ partners. The data range from $9.25^{\circ} \mathrm{W}$ to $37^{\circ} \mathrm{E}$ and include a part of the Atlantic (not included in the atlas) and the Marmara Sea. Figure 1 shows the locations of the profiles and Table 3 the main instruments of the collection. Users have to register at the Marine-ID (https://users.marine-id.org, last access: 9 July 2018) to get an account for downloading the SeaDataNet V2 data collection. Registration is done only once and thereafter users can have access not only to SeaDataNet but also to all EMODnet and Copernicus Marine Data services.

The profiles in the SeaDataNet collection come from in situ observations collected with various instruments and platforms such as CTD and bottles data by discrete water samplers operated by research vessels or other smaller vessels, bathythermographs (mechanical - MBT - or expendable - XBT). Table 3 summarizes the major numbers for temperature and salinity profiles and their temporal spanning as derived from the station type, the instrument, and the platform type.

There are 21682 vertical profiles of temperature and salinity from CTD and bottle stations with no information on the instrument used. These figures correspond to profiles before the quality control and the processing of data for preparation of climatology.

The bathythermograph data were maintained in the collection despite the incorrect fall rate and the resulting warm bias in the measurements (Wijffels et al., 2008). Yet, there is not a XBT/MBT correction for the Mediterranean as for the global ocean (https://www.nodc.noaa.gov/OC5/XBT_BIAS/ xbt_bias.html, last access: 9 July 2018). These data significantly improve the geographical coverage of the temperature 


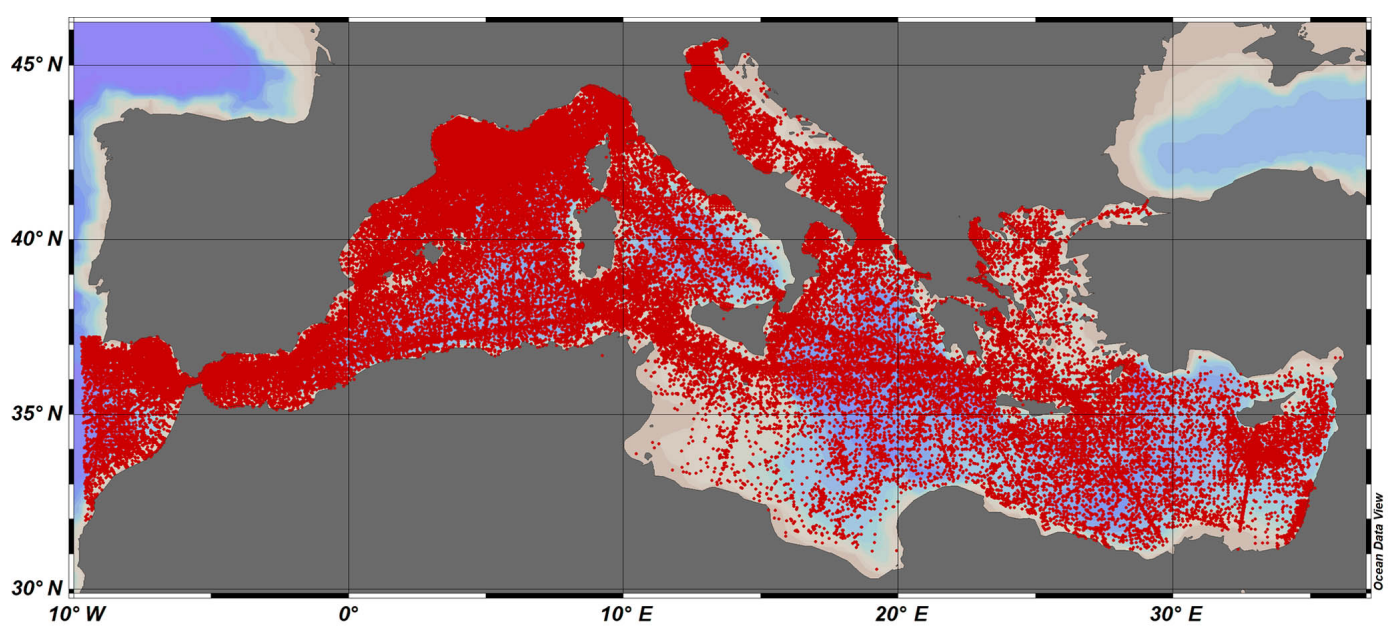

(a) Temperature

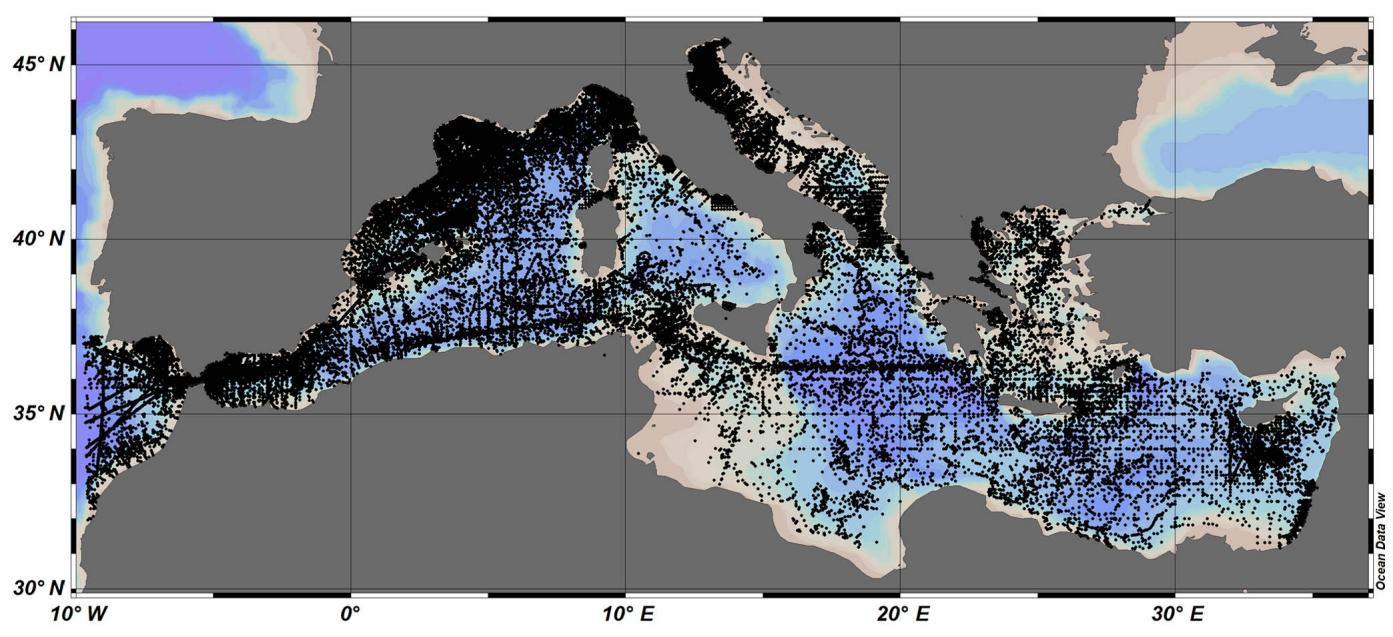

(b) Salinity

Figure 1. Geographical distribution of (a) temperature and (b) salinity profiles of the SeaDataNet V2 historical data collection (Simoncelli et al., 2015b, http://sextant.ifremer.fr/record/8c3bd19b-9687-429c-a232-48b10478581c/, last access: 9 July 2018).

records during the 1950-1985 period and reduce the resulting analysis error due to data gaps. Therefore, it was decided to keep them despite their known (small) bias.

\subsubsection{Preparation for the analysis}

The following operations were applied to the initial data before performing the analysis:

1. Data were extracted at the selected depth levels and temporal frames (months, seasons, decades, and periods).

2. Spatial binning was performed to improve the quality of the parameters (correlation length and signal-to-noise ratio) optimization by averaging a part of the highly correlated observations (taken by a research vessel in a re- stricted area, for instance). Spatial binning was applied to the data only during the parameter optimization step but then the original data (and nonbinned) were used for the analysis itself.

3. Data outside the analysis domain were excluded.

4. Weights were applied to the data to reduce the influence of a large number of data located in a small area within a short period. This is particularly useful for time series data. The characteristic length of weighting was set to be equal to $0.08^{\circ}$ and the characteristic time of weighting was set to be equal to 90 days for the seasonal analysis and 30 days for the monthly analysis. The scales were chosen according to the spatial and temporal resolution of the analysis. 
Table 1. Overview of characteristics of existing $T / S$ climatologies in Mediterranean Sea. OSD = Ocean Station Data, $\mathrm{CTD}=$ conductivity-temperature-depth, $\mathrm{MBT}=$ mechanical-digital-micro bathythermograph, XBT = expendable bathythermograph, $\mathrm{SUR}=$ surface, $\mathrm{APB}=$ autonomous pinniped bathythermograph, $\mathrm{MRB}=$ moored buoy data, $\mathrm{PFL}=$ profiling float data, $\mathrm{DRB}=\mathrm{drifting}$ buoy, $\mathrm{UOR}=$ undulating oceanographic recorder, $\mathrm{GLD}=$ glider.

\begin{tabular}{|c|c|c|c|c|}
\hline Climatology & $\begin{array}{l}\text { World Ocean Atlas } \\
2013\end{array}$ & Medar/Medatlas & SeaDataNet & Present \\
\hline Date & 2013 & 2002 & 2015 & 2017 \\
\hline Instruments/platforms & $\begin{array}{l}\text { OSD, High-resolution } \\
\text { CTD, MBT, XBT, } \\
\text { SUR, APB, MRB, } \\
\text { PFL, DRB, UOR, GLD }\end{array}$ & $\begin{array}{l}\text { MBT, XBT, discrete } \\
\text { water samplers, CTD, } \\
\text { thermistor chains }\end{array}$ & $\begin{array}{l}\text { MBT, XBT, discrete } \\
\text { water samplers, CTD, } \\
\text { thermistor chains, ther- } \\
\text { mosalinographs, DRB, } \\
\text { PFL, MRB }\end{array}$ & $\begin{array}{l}\text { MBT, XBT, discrete } \\
\text { water samplers, CTD, } \\
\text { thermistor chains, ther- } \\
\text { mosalinographs, DRB, } \\
\text { PFL, MRB }\end{array}$ \\
\hline Horizontal extent & Global & $\begin{array}{l}\text { Mediterranean, Black } \\
\text { Sea }\end{array}$ & Mediterranean Sea & Mediterranean Sea \\
\hline Parameters & $\begin{array}{l}\text { Temperature, salinity, } \\
\text { density beta version, } \\
\text { conductivity, dis- } \\
\text { solved oxygen, percent } \\
\text { oxygen saturation, } \\
\text { apparent oxygen } \\
\text { utilization, silicate, } \\
\text { phosphate, nitrate }\end{array}$ & $\begin{array}{l}\text { Temperature, salin- } \\
\text { ity, alkalinity, pH, dis- } \\
\text { solved oxygen, } \\
\text { ammonium, nitrite, } \\
\text { nitrate, phosphate, sili- } \\
\text { cates, chlorophyll- } a \text {, } \\
\text { hydrogen sulfide }\end{array}$ & Temperature, salinity & Temperature, salinity \\
\hline Horizontal resolution & $1 / 4^{\circ} \times 1 / 4^{\circ}$ & $1 / 4^{\circ} \times 1 / 4^{\circ}$ & $1 / 8^{\circ} \times 1 / 8^{\circ}$ & $1 / 8^{\circ} \times 1 / 8^{\circ}$ \\
\hline Vertical extent & $0-1500 \mathrm{~m}, 0-5500 \mathrm{~m}$ & $0-4000 \mathrm{~m}$ & $0-5500 \mathrm{~m}$ & $0-5500 \mathrm{~m}$ \\
\hline Vertical levels & $\begin{array}{l}57 \text { levels for monthly } \\
\text { fields, } 102 \text { levels for an- } \\
\text { nual, seasonal fields }\end{array}$ & 25 & 33 & 33 \\
\hline Temporal data coverage & 1864-2013 & 1890-2000 & $1900-2013$ & 1900-2015 \\
\hline Temporal resolution & $\begin{array}{l}\text { Climatic, monthly, } \\
\text { seasonal, averaged } \\
\text { periods, decadal } \\
(1955-1964,1965- \\
1974,1975-1984, \\
1985-1994,1995- \\
2004,2005-2012 \\
\text { years) }\end{array}$ & $\begin{array}{l}\text { Climatic, monthly, } \\
\text { seasonal, interannual*, } \\
\text { running } 3 \text { years*, run- } \\
\text { ning } 5 \text { years, running } \\
\text { decades* }\end{array}$ & Monthly & $\begin{array}{l}\text { Climatic, monthly, sea- } \\
\text { sonal, running decades, } \\
\text { averaged periods }\end{array}$ \\
\hline
\end{tabular}

No error fields are available for the Medar/Medatlas, interannual*, running 3-years* and running decades* computations.

Table 2. Analysis parameters for variational inverse method (VIM) implementation in the Mediterranean.

\begin{tabular}{llll}
\hline $\begin{array}{l}\text { Climatology } \\
\text { Method }\end{array}$ & $\begin{array}{l}\text { Medar/Medatlas } \\
\text { VIM }\end{array}$ & $\begin{array}{l}\text { SeaDataNet } \\
\text { DIVA (VIM) }\end{array}$ & $\begin{array}{l}\text { Present } \\
\text { DIVA (VIM) }\end{array}$ \\
\hline Correlation length & Constant & Constant & Variable \\
Signal-to-noise ratio & Variable & Constant & Variable \\
Background field & Seminormed & Seminormed & Seminormed \\
Detrending & No & No & Yes (for background fields) \\
Observation weighting & No & No & Yes \\
\hline
\end{tabular}

\subsubsection{Vertical interpolation}

The observations do not have a uniform vertical distribution and a vertical interpolation of the profiles into standard depths is needed prior to the gridding. The DIVA tool has embedded the weighted parabolic interpolation method
(Reiniger and Ross, 1968) into its workflow (Troupin et al., 2010). This method is widely used in oceanographic climatologies, such as World Ocean Atlas 2013 (WOA13) (Locarnini et al., 2013; Zweng et al., 2013) and Medar/Medatlas (MEDAR Group, 2002), as it creates less vertical instabilities. Only "good" data were used, e.g., data with quality con- 


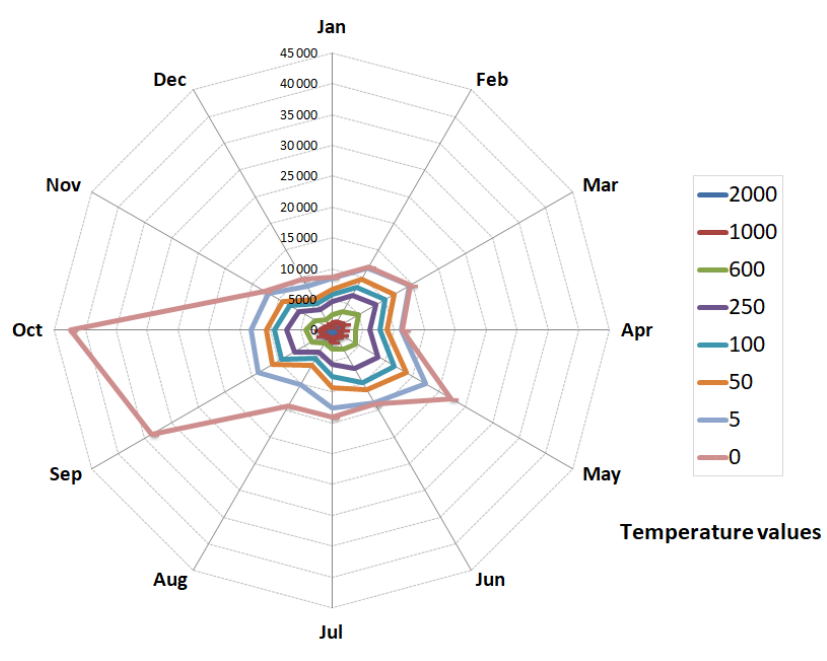

(a) Temperature

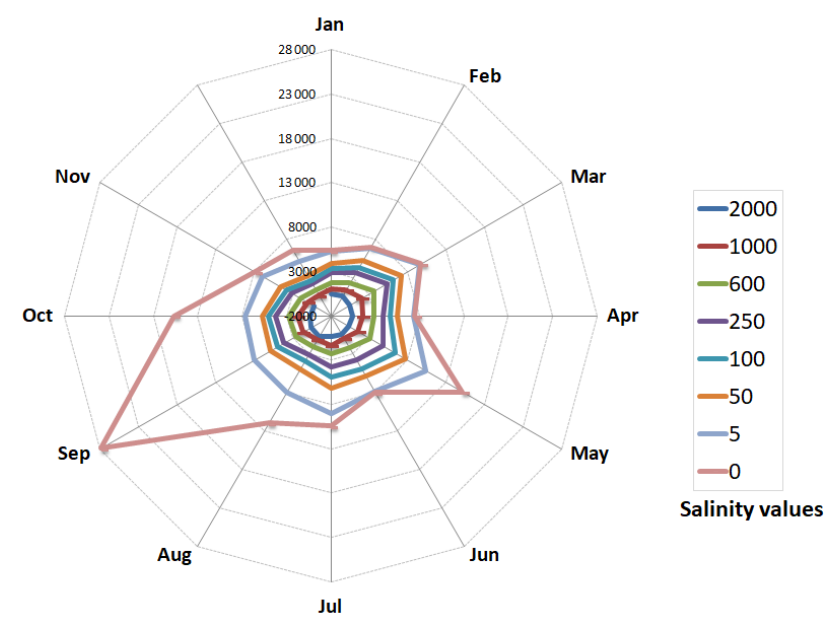

(b) Salinity

Figure 2. Number of observations per month for (a) temperature and (b) salinity.

trol flag 1 and 2 according to the SeaDataNet QC flag scale (SeaDataNet Group, 2010). The interpolation was performed onto 31 International Oceanographic Data and Information Exchange (IODE) standards depths: $[0,5,10,20,30,50,75$, $100,125,150,200,250,300,400,500,600,700,800,900$, 1000, 1100, 1200, 1300, 1400, 1500, 1750,2000, 2500, 3000, $3500,4000]$. These are the same depths as Simoncelli et al. (2014) used in the existing SeaDataNet V1.1 climatology, thus allowing quick visual intercomparisons. The WOA13 climatological fields offer a higher vertical resolution (87 depth levels from 0 to $4000 \mathrm{~m}$ ), thus facilitating higher resolution models or more accurate quality control for observational data. However, the monthly WOA 13 fields in the Mediterranean extend only down to $1500 \mathrm{~m}$. In the next releases of the present atlas, the vertical resolution will be in- creased. This version rather focuses on the improvement of the horizontal and temporal resolutions.

\subsubsection{Quality control}

Currently the SeaDataNet V2 collection is the most complete and quality-controlled data set for the Mediterranean Sea, released within SeaDataNet project. Prior to its release, it has undergone extended quality control according to the SeaDataNet standards and strategy such as elimination of duplicates, broad range checks for detecting outliers, spikes, density inversion, zero values. Regional experts performed the quality checks in close cooperation with the data originators and the responsible data centres ensuring the best result as described in Simoncelli et al. (2015b). The quality control is done with the use of the Ocean Data View tool (ODV, Schlitzer, 2002, https://odv.awi.de, last access: 9 July 2018). However, in order to avoid the influence of extremes (but not necessarily erroneous values) in the climatology, the following additional checks were applied to the data. The Mediterranean Sea was divided in 27 rectangular areas defined by Manca et al. (2004), which exhibit the typical subregional features. In each area, a mean profile was calculated at the standard depths. Values lying outside \pm 3 standard deviations around the mean were considered as "outliers" and excluded from the DIVA analysis. The percentage of data excluded from the analysis was $0.8 \%$ for the temperature and $0.9 \%$ for the salinity values. This filter with the standard deviation was applied twice at the data sets that were used as background fields and for the optimization of the analysis parameters (the correlation length, signal-to-noise ratio and variance of the background field). In the second run of the standard deviation filter, the amount of excluded data was 0.5 and $0.7 \%$ respectively.

\subsubsection{Data temporal distributions}

There is an expected seasonal distribution with more temperature and salinity profiles during summer and autumn as well as at the surface layers compared to the deeper ones (Fig. 2). However, the monthly and yearly distributions reveal a great bias for September and October and for the years 2008 and 2009. This is due to the temporary presence of 51063 thermosalinograph data, at 2 and $3 \mathrm{~m}$ depth, essentially located near the Strait of Gibraltar and in the Alboran Sea. Such irregular distribution in time has to be taken into account when computing the climatological fields otherwise the spatial interpolations will be biased towards the values of these high data coverage during these 2 months. Therefore, a detrending method was applied to the data prior to the DIVA analysis to remove this effect of uneven distribution in time. The detrending tool is provided by the DIVA software. The detrending was applied to all background fields (see paragraph below) and the monthly, seasonal, and annual climatologies. It was not applied to running decades and the 6 decadal pe- 


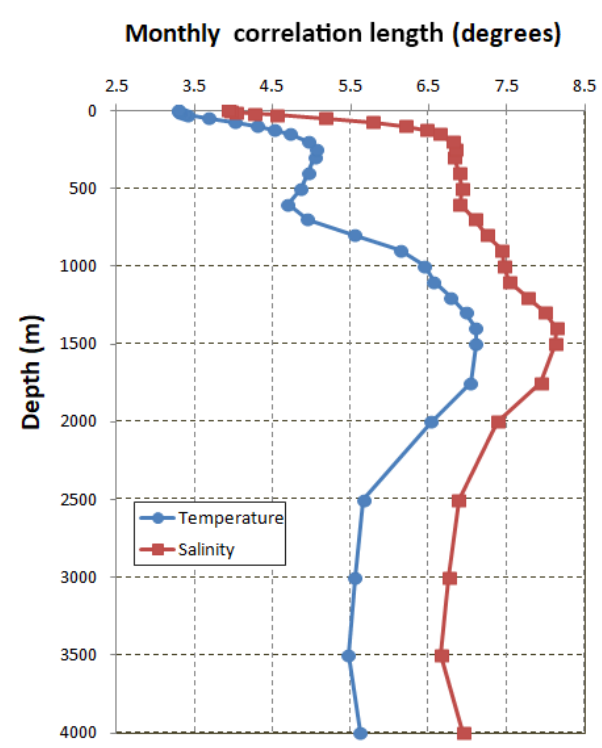

(a) Monthly averaged correlation length

Seasonal correlation length (degrees)

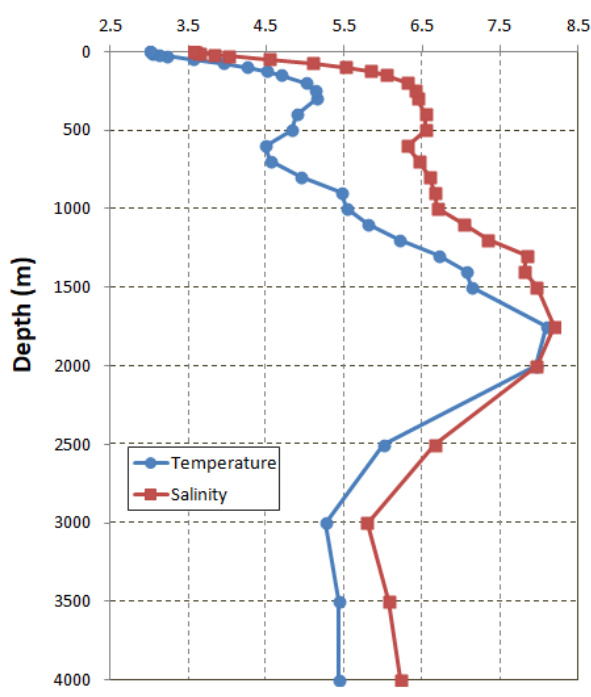

(c) Seasonal averaged correlation length

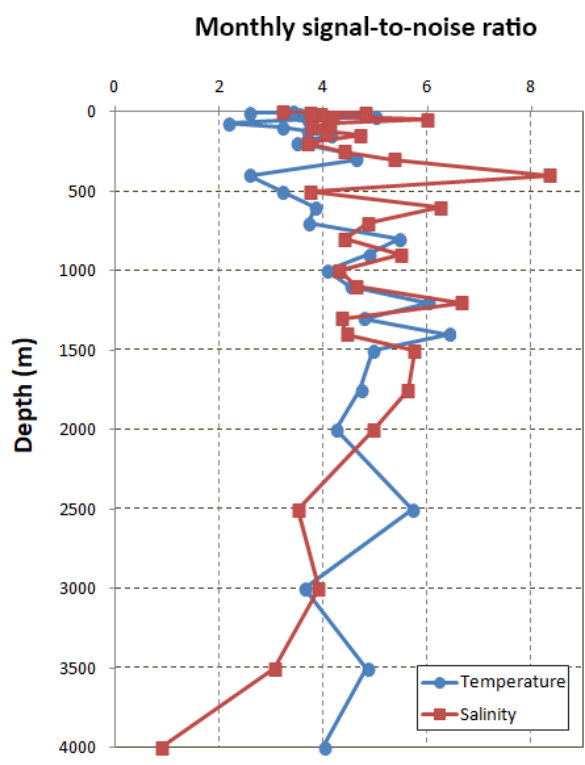

(b) Monthly averaged signal-to-noise ratio

Seasonal signal-to-noise ratio

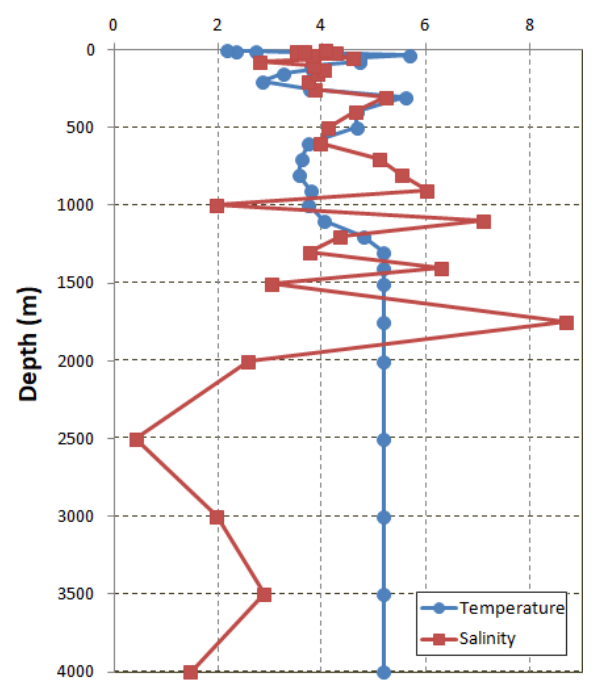

(d) Seasonal averaged signal-to-noise ratio

Figure 3. Averaged profiles of correlation length $(\mathbf{a}, \mathbf{b})$ and signal-to noise ratio $(\mathbf{c}, \mathbf{d})$ for temperature and salinity.

riod climatologies in order not to remove any of the longterm trends in temperature and salinity.

\subsubsection{Data weighting}

The influence of the uneven distribution in space where a large number of data points are concentrated in a very small area and within a very short period is controlled by applying different weights to each of these data points. Indeed, such points cannot be considered independent in a climatological analysis. So rather than calculating a super observation (similarly to binning), one can reduce the weight or, in other words, increase the error attached to each individual measurement. Points which are close in time and space will undergo such a treatment. The scales below which such a weighting is done have a characteristic length of $0.08^{\circ}$ (same unit as the data locations) and a characteristic time of 1 month ( 30 days). Typical examples where the weighting is particularly profitable are the cases of the thermosalinograph data (see previous paragraph) and time series data from coastal monitoring stations. Data weighting functionality is also provided by the DIVA tool. Both data weighting and de- 
Table 3. Data distribution per instrument, station, and platform type.

\begin{tabular}{|c|c|c|c|c|}
\hline \multirow[b]{3}{*}{ Instrument/station type } & \multirow[b]{3}{*}{ Platform type } & \multicolumn{2}{|c|}{ Number of profiles } & \multirow{3}{*}{ Period } \\
\hline & & Temperature & Salinity & \\
\hline & & & & \\
\hline CTD & $\begin{array}{l}\text { Research vessel, moored surface buoy, fixed mooring, } \\
\text { ships of opportunity, other type of vessels }\end{array}$ & 45914 & 42420 & 1964-2013 \\
\hline Discrete water samplers & Research vessel, other type of vessels & 33449 & 30423 & 1912-2009 \\
\hline Bathythermographs & Research vessel, ships of opportunity, other type of vessels & 44336 & & 1952-2014 \\
\hline Thermosalinographs & Research vessel, other type of vessels & 51063 & 29747 & 2008-2009 \\
\hline $\begin{array}{l}\text { Salinity sensors, water } \\
\text { temperature sensor }\end{array}$ & Drifting subsurface float & 8206 & 8207 & 2005-2015 \\
\hline Not provided & $\begin{array}{l}\text { Research vessel, ships of opportunity, } \\
\text { other type of vessels, unknown }\end{array}$ & 21682 & 21682 & 1914-2013 \\
\hline
\end{tabular}

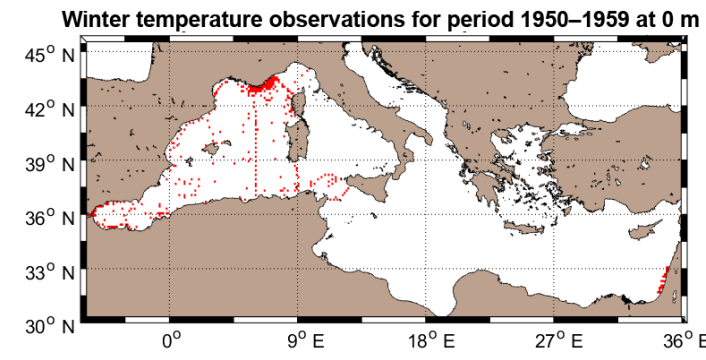

(a)

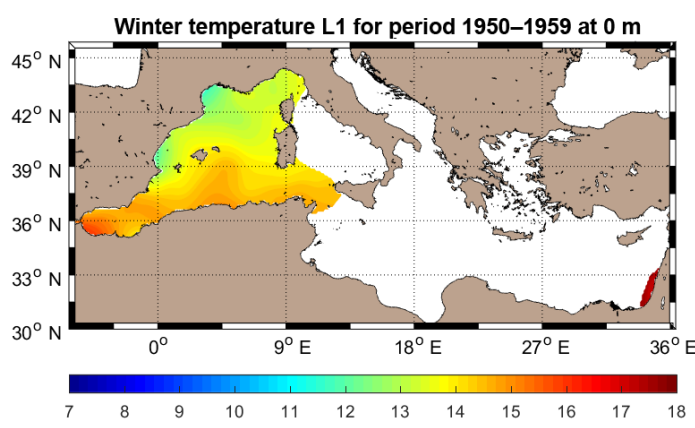

(c)

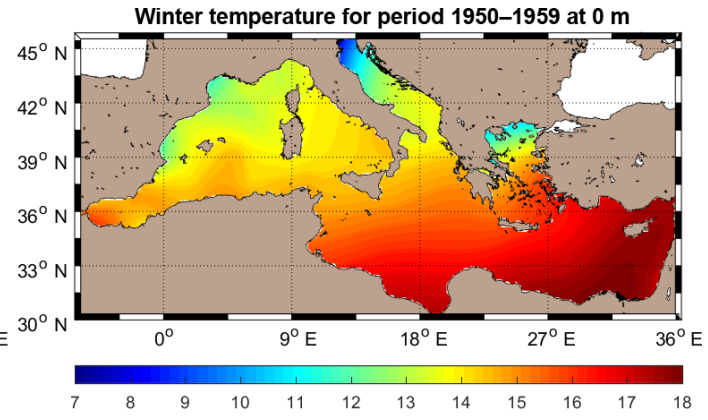

(b)

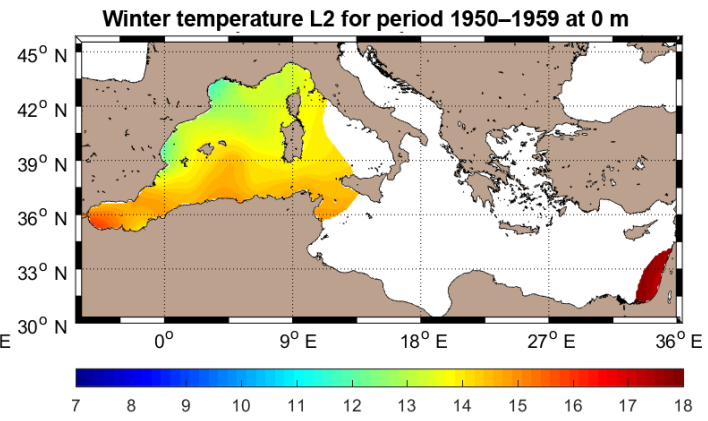

(d)

Figure 4. Example of observations distribution (a) and corresponding fields distributions depending on relative error threshold values, (b) an unmasked field, (c) a masked field with relative error threshold $=0.3$, and $(\mathbf{d})$ a masked field with relative error threshold $=0.5$.

trending techniques have been applied for the first time in the computations for the Mediterranean Sea climatologies.

\section{Method}

\subsection{The DIVA interpolation tool}

The Data-Interpolating Variational Analysis (DIVA) is a method designed to perform spatial interpolation (analysis) of sparse and heterogeneously distributed and noisy data into a regular grid in an optimal way. The basic idea of the vari- ational analysis is to determine a continuous field approximating data and exhibiting small spatial variations. In other words, the target of the analysis is defined as the smoothest fields that respects the consistency with the observations and a priori knowledge of the background field over the domain of interest. To do so, a cost function that takes into account the distance between the reconstructed field and the observations, and the regularity of the field is minimized. The solution of the minimization problem is obtained through a finiteelement technique (Rixen et al., 2000). The main advantage is that the computational cost is independent of the number 


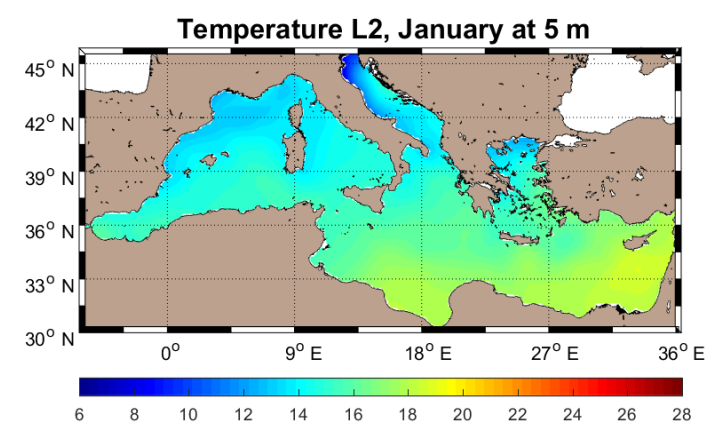

(a)

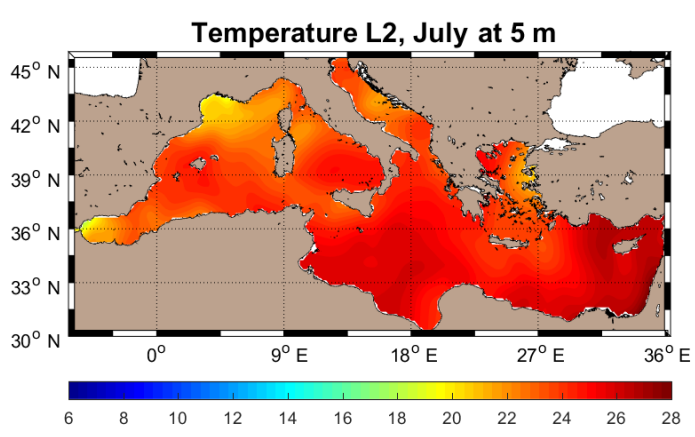

(c)

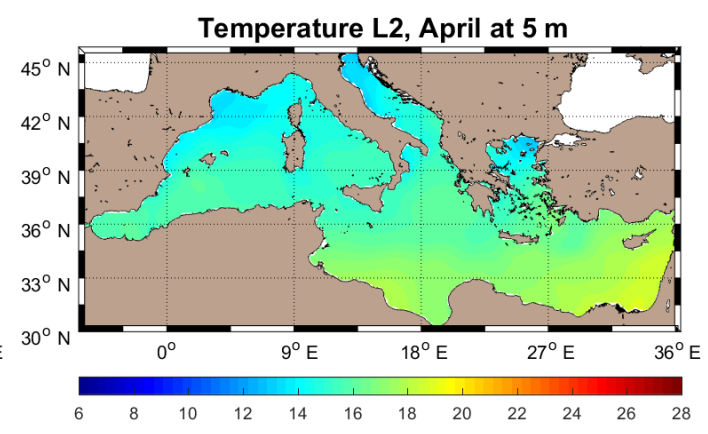

(b)

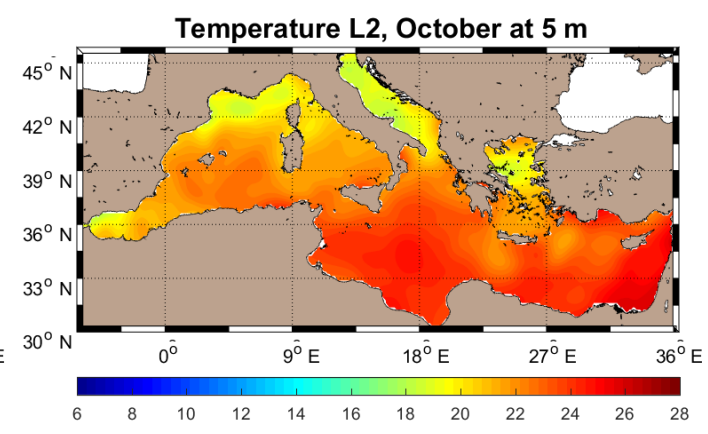

(d)

Figure 5. Surface temperature climatology at $5 \mathrm{~m}$ in (a) January, (b) April, (c) July and (d) October.

of data points analyzed; instead it depends on the number of degrees of freedom, i.e., on the size of the finite-element mesh. The mesh takes into account the complexity of the geometry of the domain without having to separate subbasins prior to the interpolation, and the mesh automatically prohibiting correlations across land barriers. Among other major advantages of the method, DIVA can take into account dynamic constraints allowing for anisotropic spatial correlation. Tools to generate the finite-element mesh are provided as well as tools to optimize the parameters of the analysis. The signal-to-noise ratio is optimized by a generalized cross-validation (GCV) technique (Brankart and Brasseur, 1996) while the correlation length is estimated by comparing the relation between the empirical data covariance and the distance against its theoretical counterpart (Troupin et al., 2017). Along with the analysis gridded fields, DIVA also provides error fields (Brankart and Brasseur, 1998; Rixen et al., 2000) based on the data coverage and their noise. The method computes gridded fields in two dimensions. The three-dimensional $(x, y, z)$ and four-dimensional extensions $(x, y, z, t)$ have been embedded into the interpolation scheme with an emphasis on creating climatologies. Detailed documentation of the method can be found in Troupin et al. (2010, 2012) and in the Diva User Guide (Troupin et al., 2017). The current atlas has been produced with the use of DIVA 4.6.11 (Watelet et al., 2015a) with a Linux Ubuntu 16.04.3 operating system.

\subsection{Topography and coastlines}

The domain where the interpolation has to be performed is covered by a triangular finite-element mesh that follows the coastline. The bathymetry used for coastline definitions and mesh generation is based on the General Bathymetric Chart of the Oceans (GEBCO) 1 min topography. Since the subsequent analyses focus on much larger scales than $1 \mathrm{~min}$, the resolution of the topography was downgraded to $5 \mathrm{~min}$, still fine enough to resolve topological features such as islands and straits, yet coarse enough to be coherent with the scales of interest. The step of the output grid was set to $1 / 8^{\circ}$ for similar reasons. The geographical boundaries of the region were set to $30-46^{\circ} \mathrm{N}, 6.25^{\circ} \mathrm{W}-36.5^{\circ} \mathrm{E}$. The depth contours that define the two-dimensional horizontal planes where the interpolation takes place are the 31 standard depth levels from 0 to $4000 \mathrm{~m}$.

\subsection{Finite-element mesh}

Once the depth contour files at the specified 31 standard depth levels were prepared, the mesh was generated using an initial correlation length $L_{\mathrm{c}}$ equal to $0.5^{\circ}$, which means the initial size $L_{\mathrm{e}}$ of each finite triangular element is equal to $0.167^{\circ}\left(L_{\mathrm{c}} / 3\right)$. The initial $L_{\mathrm{c}}$ scale was made as small as allowed by computing resources. This length scale is much smaller than the length scales for the analysis (typically a few degrees) and it ensures that the finite-element solution is 


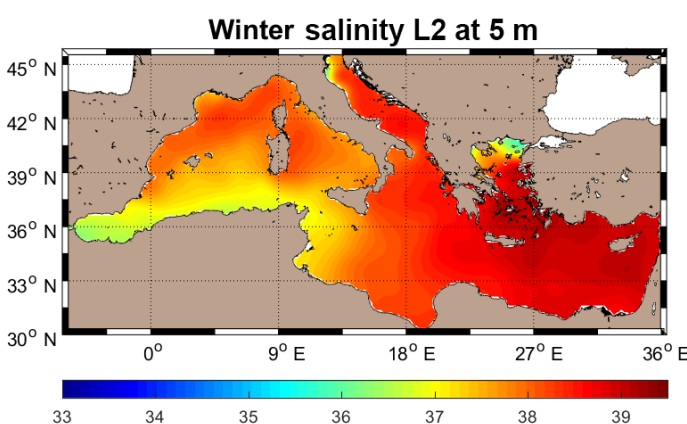

(a)

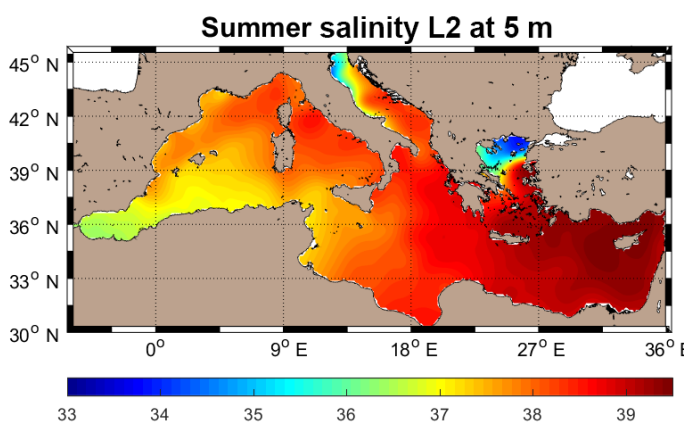

(c)

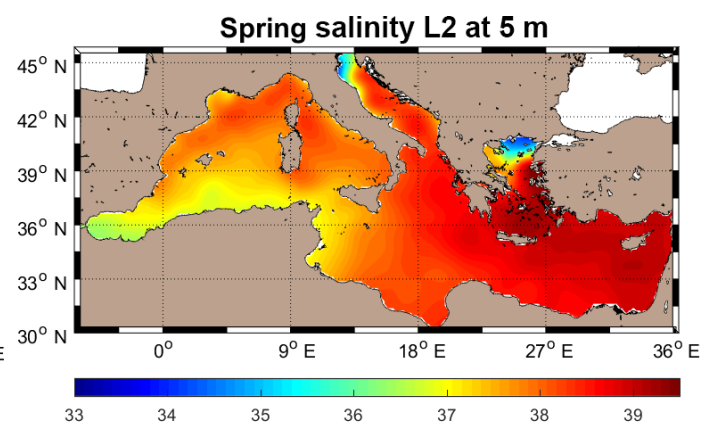

(b)

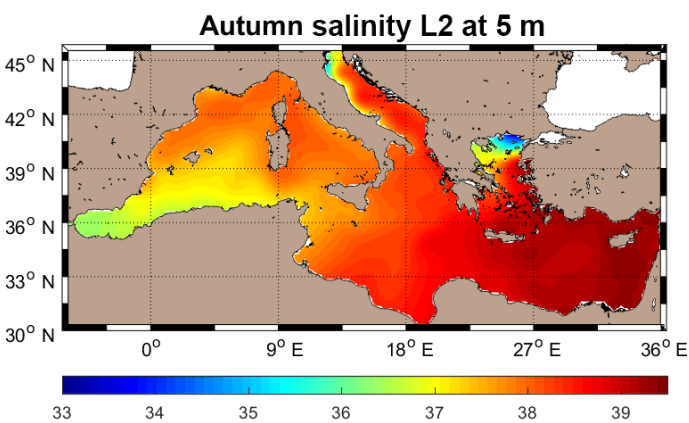

(d)

Figure 6. Surface salinity climatology at $5 \mathrm{~m}$ for (a) winter, (b) spring, (c) summer, and (d) autumn.

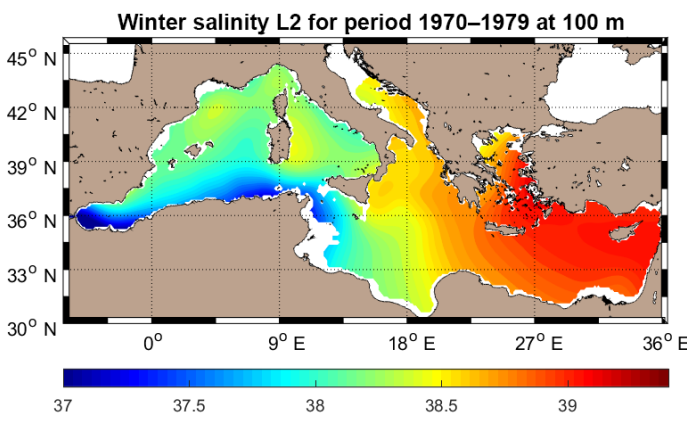

(a)

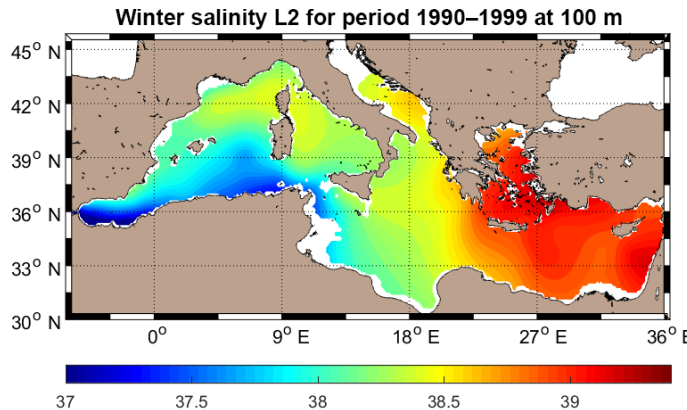

(c)

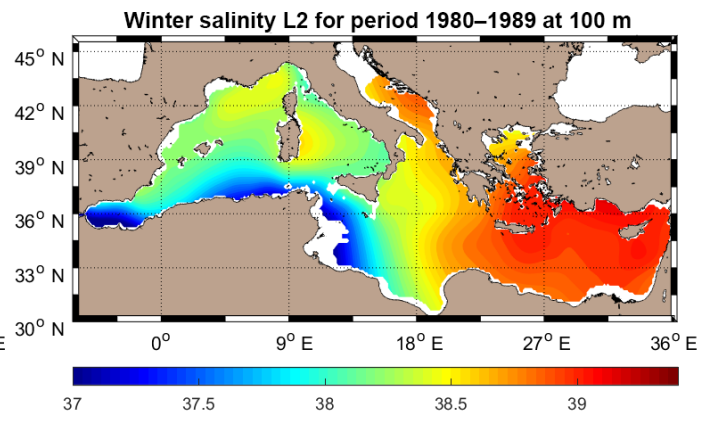

(b)

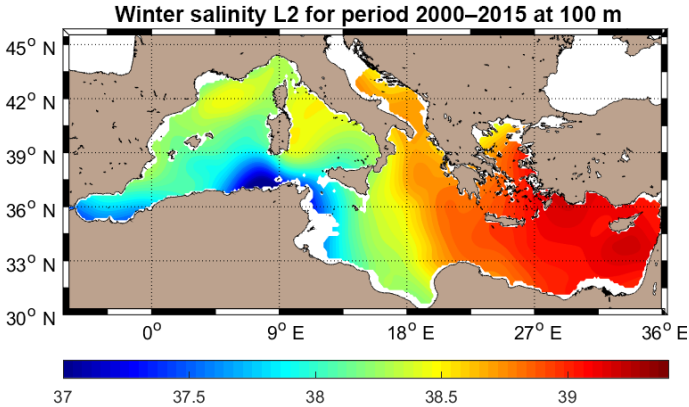

(d)

Figure 7. Winter salinity at $100 \mathrm{~m}$ for four periods: (a) 1970-1979, (b) 1980-1989, (c) 1990-1999, (d) 2000-2015. 
solving the mathematical DIVA formulation with very high precision (it does not mean that the analysis is the truth, but that the numerical solution is actually close to the mathematical solution of the variational formulation; in other words, the discretization does not add further errors into the analysis than the analysis method and the data themselves). The mesh was generated once and used in each repetition of the analysis.

\subsection{Interpolation parameters}

\subsubsection{Correlation length}

The correlation length $\left(L_{\mathrm{c}}\right)$ is the radius of influence of data points. It can be determined objectively using a specific DIVA tool that takes into account the data distribution, or the correlation length can be provided a priori by the user according to its (subjective) experience on expected patterns occurring in the domain of interest. In the contrary to the SeaDataNet climatology where a constant value used in all depths, in this atlas, the correlation length was defined as follows. For the monthly climatology, the correlation length was calculated for every month (for all years from 1950 to 2015) and at each depth by fitting the empirical data covariance as a function of distance by its theoretical function. It was then smoothed by applying a vertical filtering, similarly to Troupin et al. (2010). Then, these monthly correlation length profiles were averaged together in order to have a smooth transition from one month to another. Indeed, the estimated correlation lengths at the surface vary between 1.8 (July) and $3.6^{\circ}$ (December). For the seasonal and the annual climatologies, the correlation length was calculated for every season and depth (from all years between 1950 and 2015), filtered vertically and then averaged into a single profile. This approach yields slightly smaller correlation lengths than the averaging per month and in combination with the rest of the analysis parameters, the fields are not so smoothed and are closer to the data. The mean profiles for temperature and salinity are shown in Fig. 3a and c. There is a general increase from the surface to $2000 \mathrm{~m}$ except in a layer from 300 to $600 \mathrm{~m}$ where it decreases. Also there is a decrease from around 2000 to $3000 \mathrm{~m}$ in both cases that can be attributed to the variability of the intermediate and deep waters in the Mediterranean.

\subsubsection{Signal-to-noise ratio}

The signal-to-noise ratio $(\mathrm{S} / \mathrm{N})$ represents the ratio of the variance of the signal to the variance of observational errors. When measuring a variable, there is always an uncertainty on the value obtained. Noise does not only take into account instrumental errors (which are generally low), but it also includes the following:
1. the representativeness errors, meaning that what one measures is not always what one intends to analyze (e.g., skin temperature, inadequate scales);

2. the synopticity errors, occurring when the measurements are assumed to be taken at the same time (e.g., data from a cruise; Rixen et al., 2001).

Because of the multiple sources of error, a perfect fit to observations is thus not advised. In the case of climatology, the main cause of error is not the instrumental error but the representativeness errors, which cannot easily be quantified. In this atlas, unlike the SeaDataNet (Simoncelli et al., 2014, 2016) and other regional climatologies (Troupin et al., 2010), a variable $\mathrm{S} / \mathrm{N}$ was defined following the same approach as with the correlation length. The mean monthly and seasonal $\mathrm{S} / \mathrm{N}$ profiles for temperature and salinity were vertically filtered. The remaining extremes were further filtered out manually by replacing them with the mean of the adjacent layers. The seasonal mean profile for temperature was further filtered out to a constant value from 1300 to $4000 \mathrm{~m}$. In the first $500 \mathrm{~m}$ (see Fig. 3b and d), both the monthly and seasonal profiles display similar behaviors with a mean value ranging from 3.5 to 4.5 , with an exception of the monthly mean value for salinity at $400 \mathrm{~m}$.

\subsection{Background field}

The background field is the first guess of the gridded field (analysis) to reconstruct. First of all, this background is subtracted from data. Then, the variational analysis is performed by DIVA using these data anomalies as an input. Lastly, the background is added to the solution so that original data and final analyses are both expressed as absolute values. In areas with very few or no data, the analysis tends to the background field since the data anomalies are close to zero (Brankart and Brasseur, 1998). In this atlas, a seminormed analysis field (roughly speaking an analysis only capturing very large scales) was chosen as the background in order to guarantee the solution is most realistic in areas void of data. Depending on the type of climatology and gridded fields, two different background fields were used: (a) a climatic seasonal field to account for seasonality from the original data, and (b) a climatic annual field to account for interannual variability. The same correlation lengths and signal-to-noise ratios were used as for the atlas computations (see previous paragraph). Analytically the following background fields were produced:

1. climatic seasonal seminormed analysis as background for the decadal seasonal fields of temperature and salinity;

2. climatic annual seminormed analysis as background for the decadal annual fields of temperature and salinity;

3. climatic seasonal seminormed analysis as background for the periodical seasonal fields of temperature and salinity; 


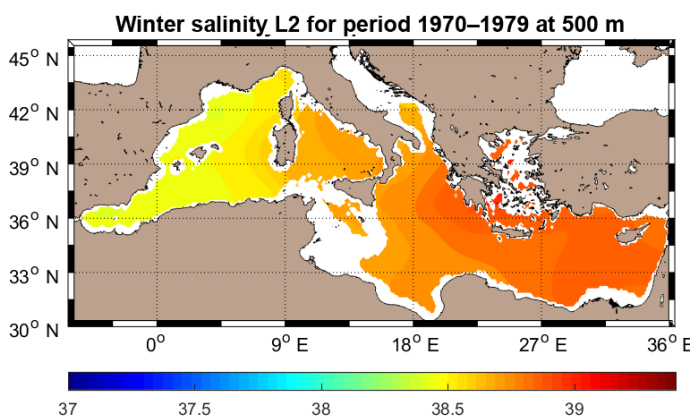

(a)

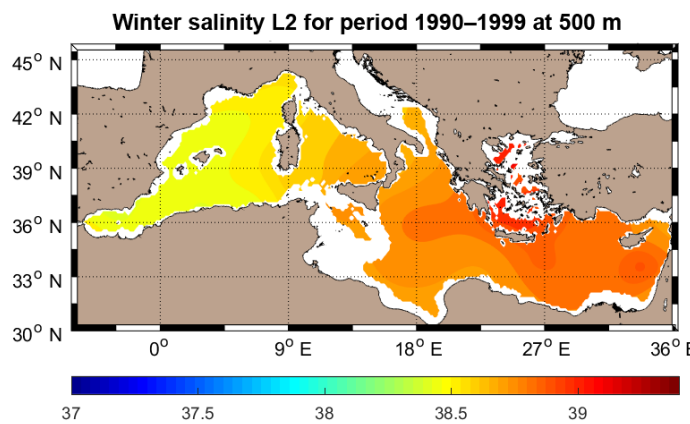

(c)

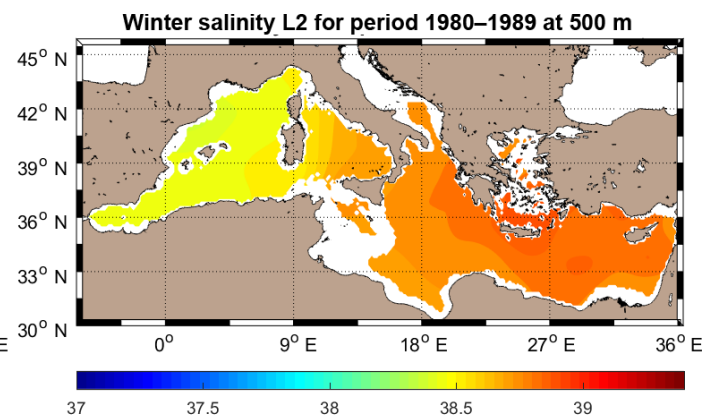

(b)

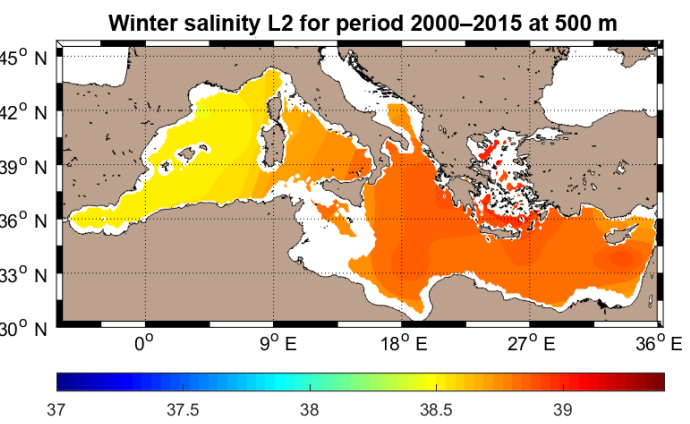

(d)

Figure 8. Winter salinity at $500 \mathrm{~m}$ for four periods: (a) 1970-1979, (b) 1980-1989, (c) 1990-1999, (d) 2000-2015.

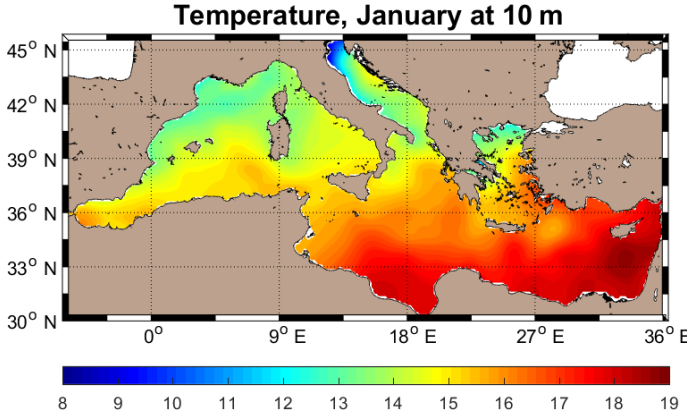

(a)

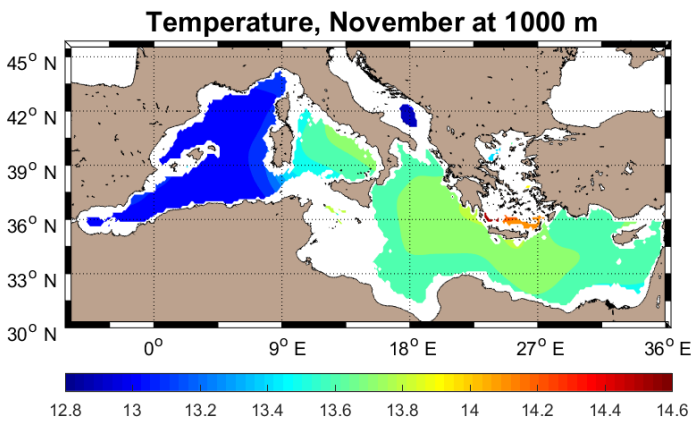

(c)

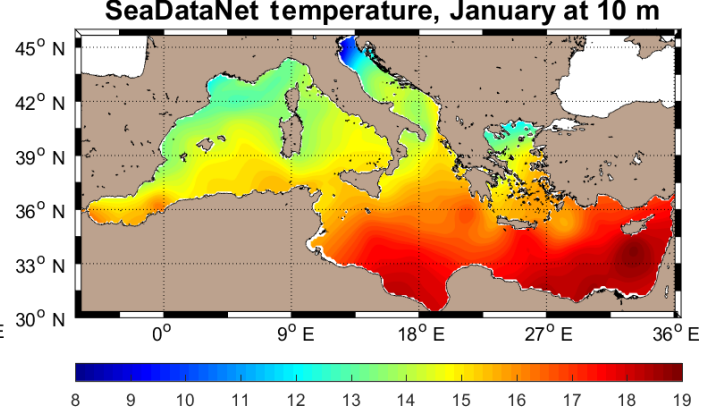

(b)

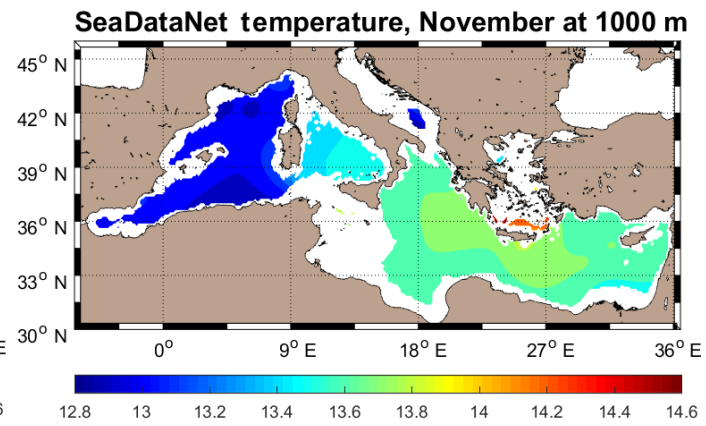

(d)

Figure 9. Comparison of atlas temperature (a, c) and SeaDataNet climatology (b, d) between January at $10 \mathrm{~m}(\mathbf{a}, \mathbf{b})$ and November at $1000 \mathrm{~m}(\mathbf{c}, \mathbf{d})$. 


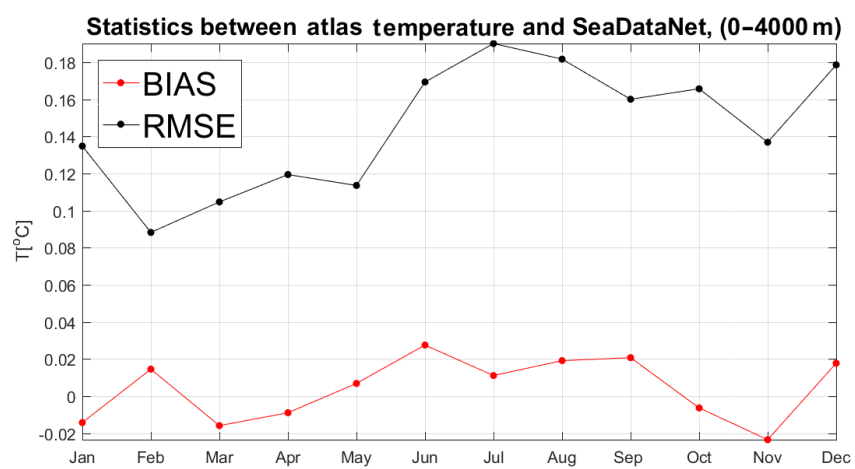

(a) Temperature

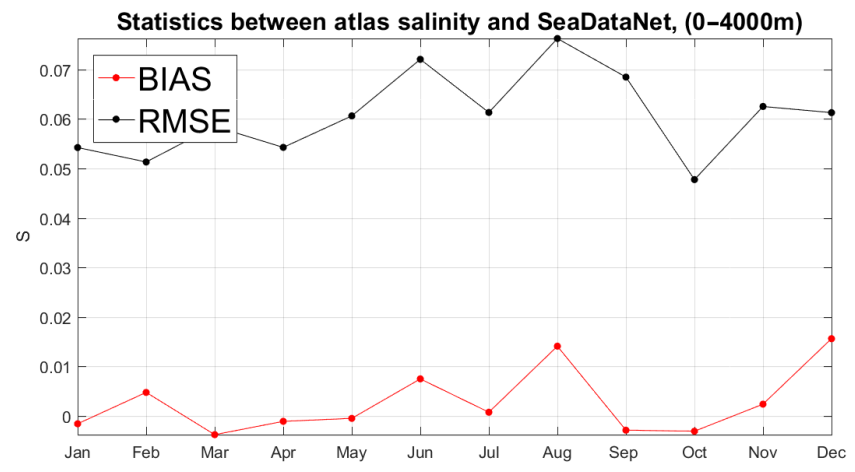

(b) Salinity

Figure 10. Basin vertical averages of BIAS and RMSE between the atlas and SeaDataNet monthly temperature (a), and monthly salinity (b) climatologies.

4. climatic annual seminormed analysis as background for the periodical annual fields of temperature and salinity;

5. climatic seasonal seminormed analysis as background for the monthly and seasonal climatology;

6. data mean value as background for the annual climatologies.

Additional monthly and seasonal climatologies were computed using the data mean value as background (the data mean value is subtracted from the data values).

The background climatic seasonal and annual fields were detrended in order to remove any seasonal and interannual trends that are due to nonuniform spatial data distribution (Capet et al., 2014). A characteristic example is the nonuniform distribution of thermosalinographs. Also, the monthly, seasonal and annual climatologies were detrended. A future goal is to apply the detrending for the estimation of the biases induced in the temperature data due to instrumental errors such as the bathythermographs.

\section{Climatological gridded fields}

The content of the atlas is described in Sect. 1. For each gridded error field, maps are provided that allow one to assess the reliability of the gridded fields and to objectively identify areas with poor coverage. DIVA provides two different errors, the relative (from 0 to 1 ) and the absolute errors (expressed in physical parameter units), which depend on the accuracy of the observations and their distribution. The relative error has been chosen in this atlas and two threshold values are used (equal to 0.3 or 0.5 ) for the quality assessment of the results (Fig. 4).

\subsection{Description of the gridded fields}

While the physical interpretation of the maps is not in the scope of this paper, it is worth noting that the main physical processes are well resolved both in space and time, such as the following:

1. the clear signature of the temperature and salinity gradient from west to east, shown in all monthly, seasonal and annual plots at all depths;

2. the temperature and its seasonal cycle;

3. the Rhodes gyre with the low temperatures is evident in all plots of temperature at surface layers regardless of month or season;

4. the Black Sea outflow with the low temperature and salinity values, which is evident in the surface plots, regardless of month or season.

Figure 5 illustrates the surface temperature at $5 \mathrm{~m}$ in January, April, July, and October and represents the seasonal cycle of the thermal field with a mean shift of $9^{\circ} \mathrm{C}$ between January and July. The western Mediterranean exhibits smaller temperatures than the eastern basin. The differences between the northern and southern regions (meridional gradient) are also very well represented. The Rhodes Gyre, identified by minimum temperature values, is distinguished southeast of Crete island, mainly at spring and autumn periods.

Some representative seasonal distributions of salinity at $5 \mathrm{~m}$ are shown in Fig. 6. The signal of the fresh Atlantic water $(S \approx 36.5 \mathrm{ppt})$ and its flow along the Algerian coast towards the eastern basin through the Sicily Strait is very evident. We can also notice the areas of low salinity due to river runoffs such as the north Adriatic and the north Aegean Sea that is influenced by the Dardanelles outflow.

Winter salinity fields at 100 and $500 \mathrm{~m}$ respectively are shown in Figs. 3.1 and 3.3 for the last four periods (19701979, 1980-1989, 1990-1999, and 2000-2015). There is a homogeneous increasing trend from west to east compared to the surface. The salinity range is between about 37 and $38.6 \mathrm{ppt}$ at $100 \mathrm{~m}$ at the western Mediterranean, while the periods $1980-1989$ and 2000-2015 are characterized by higher 


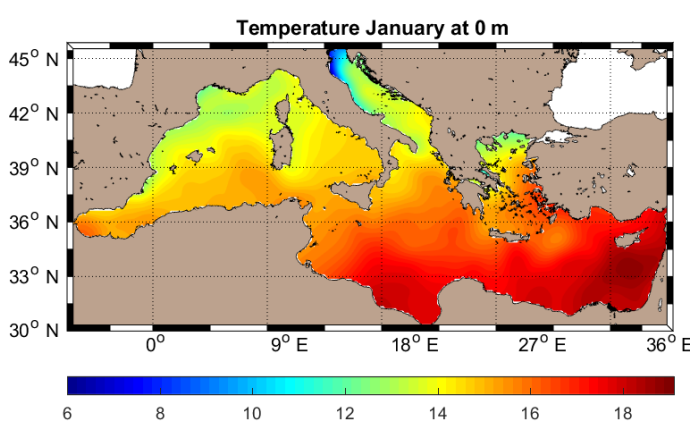

(a)

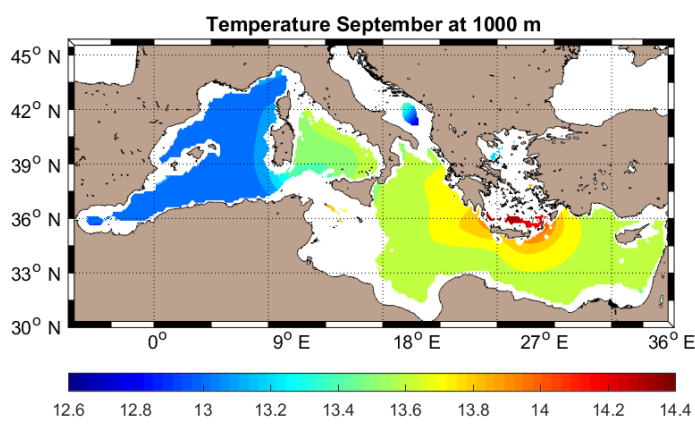

(c)

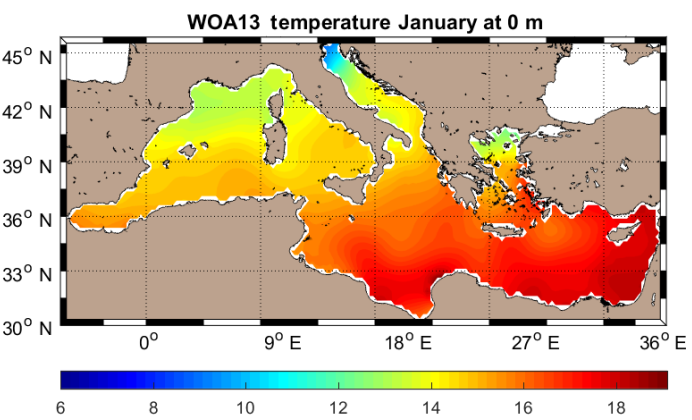

(b)

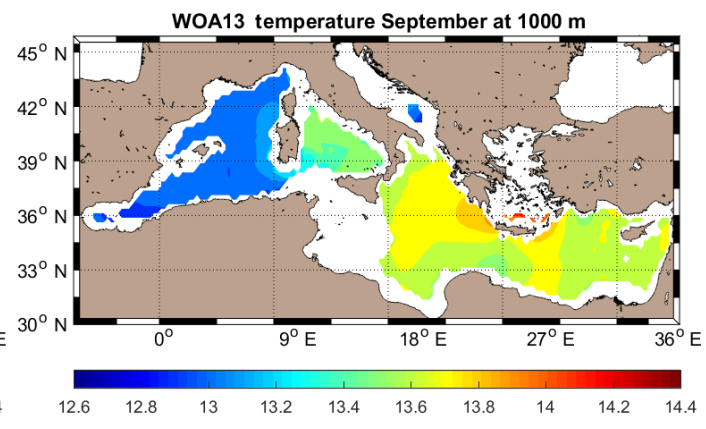

(d)

Figure 11. Comparison of atlas temperature (a, c) and WOA13 climatology (b, d) between January at $0 \mathrm{~m}(\mathbf{a}, \mathbf{b})$ and September at $1000 \mathrm{~m}(\mathbf{c}$, d).

salinities compared to the other periods. Maximum values are found in the south Adriatic at $38.9 \mathrm{ppt}$ in the period 1980-1989 and 38.8 ppt in the period 2000-2015. In the eastern Mediterranean, the salinity is between about 38.4 and $39.4 \mathrm{ppt}$ at $100 \mathrm{~m}$ with the maxima found in the Levantine basin and Aegean Sea. The last period 2000-2015 is on average more saline than the previous ones, and the thermohaline circulation patterns (such as the Shikmona Gyre) are more intense.

In the western basin there is a characteristic increase in salinity at $500 \mathrm{~m}$ compared to at $100 \mathrm{~m}$, where it is between about 38.4 and $38.7 \mathrm{ppt}$. This increase is due to the mixing with LIW that flows towards the Strait of Gibraltar. The Tyrrhenian Sea has higher salinities in the periods 19701979 and 2000-2015. In the eastern Mediterranean the salinity is between about 38.4 and 39.2 ppt, with the highest values in the north and south Aegean Sea and the period 20002015 showing higher salinity than the previous years.

\subsection{Comparison with SeaDataNet climatology}

For the current atlas, a direct comparison with SeaDataNet V1.1 climatology (Simoncelli et al., 2015a, 2016, https://doi.org/10.12770/90ae7a06-8b08-4afe-83ddca92bc99f5c0) is performed using statistical indexes like bias (differences between the two climatologies) and RMSE (root-mean-square error) implemented by Simoncelli et al. (2015a, 2016), during the SeaDataNet 2 project, as consistency analysis among different climatological products. The SeaDataNet V1.1 climatology is defined between $9.25^{\circ} \mathrm{W}-36.5^{\circ} \mathrm{E}$ of longitude and $30-46^{\circ} \mathrm{N}$ of latitude with a horizontal resolution of $1 / 8^{\circ} \times 1 / 8^{\circ}$ on 30 IODE vertical standard levels from 0 to $4000 \mathrm{~m}$. DIVA software version 4.6 .9 (Watelet et al., 2015b) has been used for both the analysis and background field computation. The salinity background field has been computed through annual seminormed analysis considering all available observations, while for temperature, 3-month seminormed background fields centered on the analysis month have been considered due to the large temperature seasonal variability. Figure 9 shows temperature distributions for atlas and SeaDataNet climatology, for January at $10 \mathrm{~m}$ and November at $1000 \mathrm{~m}$. There is very good consistency between both products. The same good agreement exists among other months and depths (not shown here). In surface distributions (at $10 \mathrm{~m}$ ), the data weighting applied in the atlas (Fig. 9a) has reduced the extension of the influence of Po river.

Statistical indexes like bias (differences between the two climatologies) and RMSE (root-mean-square error) show very good agreement too. Figure 10 shows the basin vertical averages of bias and RMSE between the atlas and SeaDataNet monthly temperature (a) and monthly salinity (b) 
climatologies. Higher differences occur in spring and autumn, and the atlas is $0.03^{\circ} \mathrm{C}$ warmer than SeaDataNet in June and less warm by $0.02{ }^{\circ} \mathrm{C}$ in November. Temperature RMSE values are ranging between 0.09 in February and 0.19 in July. Maximum differences between the two climatologies are located in the first layers (not shown here) for all months. The atlas has slightly higher salinity values than SeaDataNet salinity values in August and December and the mean bias value throughout the year is 0.003 . Salinity RMSE values are ranging between 0.048 and 0.076 . As for temperature, maximum differences are located in the first layers for all months.

\subsection{Comparison with World Ocean Atlas (WOA13)}

WOA13 provides objectively analyzed annual, seasonal, and monthly fields covering the time period 1955-2012 (average of 6 decadal means) and 6 decades: 1955-1964, 19651974, 1975-1984, 1985-1994, 1995-2004, 2005-2012. Each decadal climatology consists of annual (computed as 12-month averages); seasonal (winter: January-March; spring: April-June; summer: July-September; fall: OctoberDecember), computed as 3-month averages; and monthly fields (above $1500 \mathrm{~m}$ ). Annual, seasonal, and monthly temperature and salinity fields are available on $1^{\circ} \times 1^{\circ}$ and $1 / 4^{\circ} \times 1 / 4^{\circ}$ latitude-longitude grids. All annual and seasonal fields were calculated from 0 to $5500 \mathrm{~m}$ depth on 102 standard levels. Monthly fields are available only above $1500 \mathrm{~m}$ on all grids on 57 standard levels. Figure 11 shows temperature fields for the atlas and WOA13 for January at $0 \mathrm{~m}$ and for September at $1000 \mathrm{~m}$. At the surface, the atlas is able to represent the January mean state with more detail.

The statistical indexes applied to SeaDataNet V1.1 climatology have been calculated also for WOA2013, as in Simoncelli et al. (2015a, 2016), and they show a very good agreement between both monthly $T / S$ climatologies. Figure 12 shows the basin vertical averages of bias and RMSE between the atlas and WOA13 monthly temperature (a) and monthly salinity (b) climatologies. Temperature bias is always positive, indicating that the atlas is slightly warmer than the WOA13 climatology. Atlas salinity is less than the WOA13 at an average of 0.007 throughout the whole year.

\subsection{Comparison with Medar/Medatlas Climatology}

The Medar/Medatlas climatology was computed using the variational inverse method as the current atlas. Correlation length was fixed a priori to a constant value according to the a priori knowledge of typical scales of parameters in the domain of interest. The signal-to-noise ratio was calibrated by a generalized cross-validation technique. Data closer than $15 \mathrm{~km}$ from the coast or in areas shallower than $50 \mathrm{~m}$ were rejected in order to avoid the influence of coastal features on open sea (Rixen et al., 2005).

The impact of such as rejection can be seen in Fig. 13: in the north Adriatic Sea and in the north Aegean Sea, the

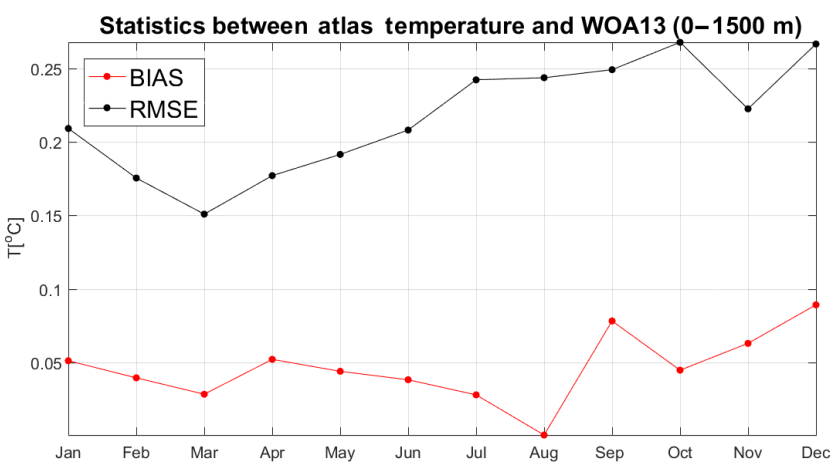

(a) Temperature

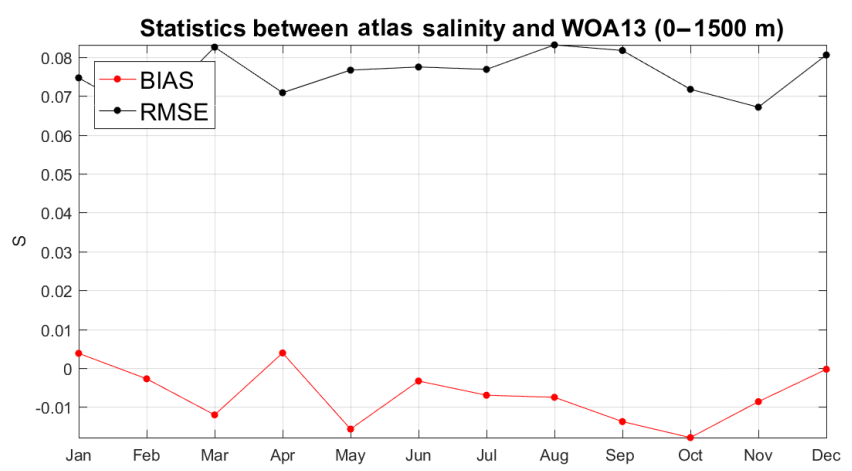

(b) Salinity

Figure 12. Basin vertical averages of BIAS and RMSE between atlas and WOA13 monthly temperature (a), and monthly salinity (b) climatologies.

influence of Po river and Black Sea outflows during winter is not captured.

The temperature at $10 \mathrm{~m}$ for the decade $1991-2000$ is shown below for the atlas (Fig. 14a) and the Medar/Medatlas climatology (Fig. 14b). The Medar/Medatlas profiles extend until 2000 , so this decade was chosen as the most complete one since there is no error field available to mask regions empty of data.

As it can be seen in Fig. 14, the current atlas describes with more detail the several features of the general circulation pattern.

\section{Code and data availability}

The dataset used in this work (Simoncelli et al., 2015b, http://sextant.ifremer.fr/record/ 8c3bd19b-9687-429c-a232-48b10478581c/) is available from the SeaDataNet catalogue at https: //www.seadatanet.org/Products. Updated versions will be released periodically.

The DIVA source code is distributed via GitHub at https://github.com/gher-ulg/DIVA (last access: 9 July 2018). 


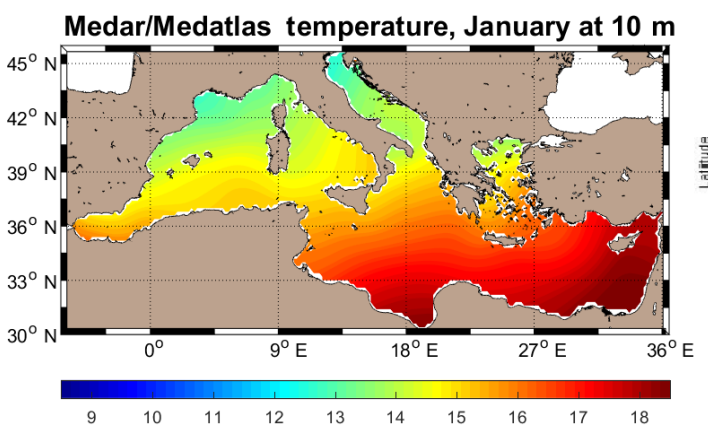

(a)

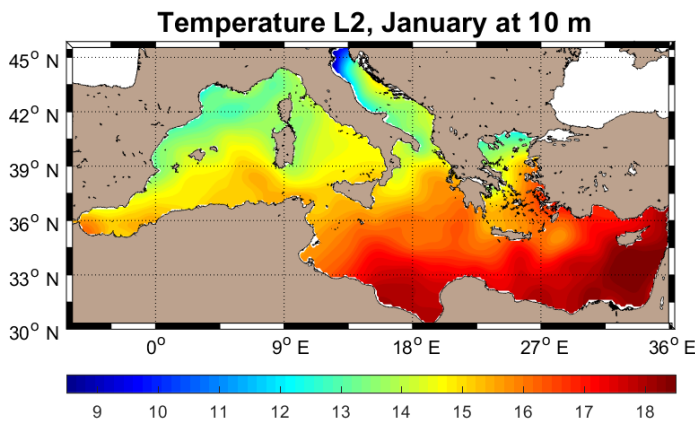

(c)

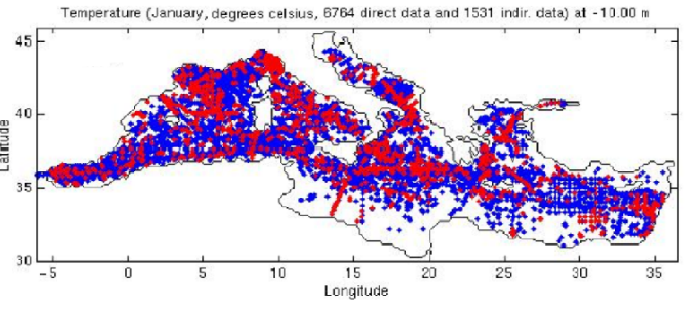

(b)

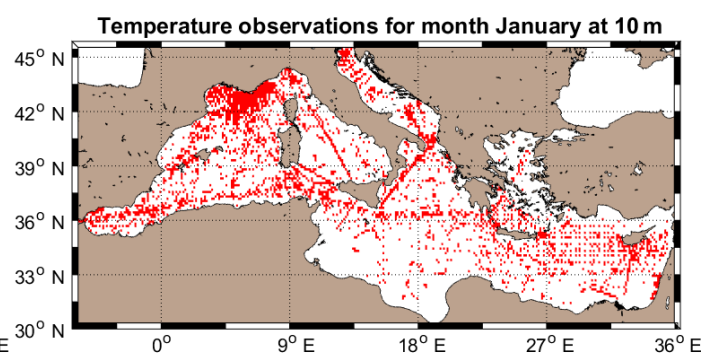

(d)

Figure 13. January temperature at $10 \mathrm{~m}$ : (a) Medar/Medatlas, coastal data removed from the analysis; (b) data used (imported from http:// modb.oce.ulg.ac.be/backup/medar/JPGSTATIONS/medar.01.med.temp.23.3.0.stations.jpg, last access: 9 July 2018); (c) current climatology, coastal data included; (d) data used.

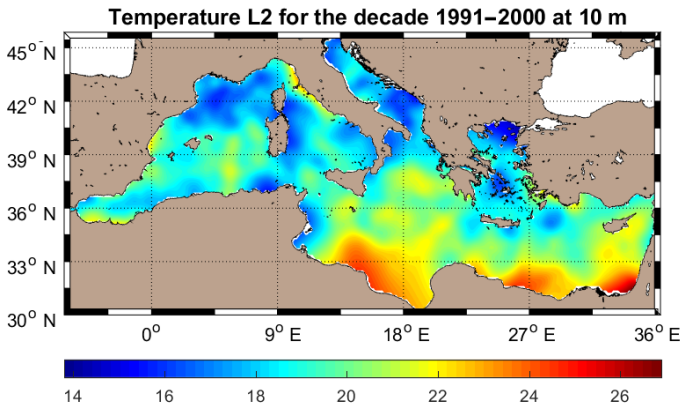

(a)

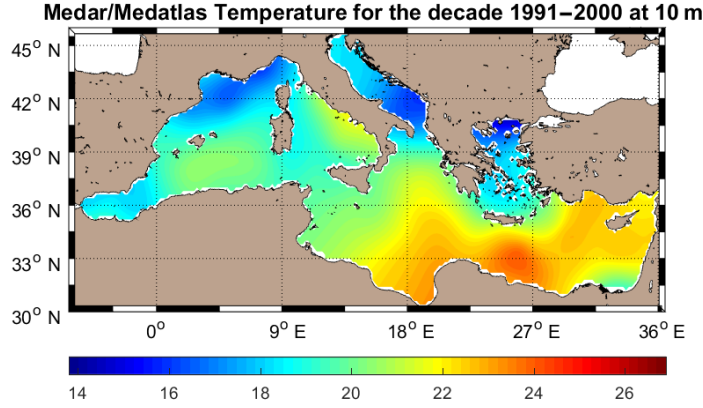

(b)

Figure 14. (a) Atlas masked temperature field for the decade 1991-2000 at 10 m, (b) Medar/Medatlas temperature field for the decade 1991-2000, at $10 \mathrm{~m}$ (no error field is available).

The different versions of the software tool are archived and referenced in Zenodo platform under the DOI: https://doi.org/10.5281/zenodo.592476.

The atlas itself is distributed through Zenodo according to the following subproducts: annual climatology: https://doi.org/10.5281/zenodo. 1146976 (Iona, 2018a); seasonal climatology for 57 running decades from 1950-1959 to 2006-2015: https://doi.org/10.5281/zenodo.1146938 (Iona, 2018b); seasonal climatology: https://doi.org/10.5281/zenodo.1146953
(Iona, 2018c). annual climatology for 57 running decades from 1950-1959 to 2006-2015: https://doi.org/10.5281/zenodo.1146957 (Iona, 2018d); seasonal climatology for six periods: 1950-1959, 1960-1969, 1970-1979, 1980-1989, 1990-1999, 20002015: https://doi.org/10.5281/zenodo.1146966 (Iona, 2018e); annual climatology for six periods: 1950 1959, 1960-1969, 1970-1979, 1980-1989, 1990-1999, 2000-2015: $\quad$ https://doi.org/10.5281/zenodo.1146970 
(Iona, 2018f); monthly climatology: https://doi.org/10.5281/zenodo.1146974 (Iona, 2018g).

\section{Conclusions}

A new, high-resolution atlas of temperature and salinity for the Mediterranean Sea for the period 1950-2015 is presented. The analysis is based on the latest SeaDataNet V2 dataset (Simoncelli et al., 2015b, http://sextant.ifremer.fr/ record/8c3bd19b-9687-429c-a232-48b10478581c/), providing the most complete, extended, and improved collection of in situ observations.

The results describe well the expected distributions of the hydrological characteristics and reveal their long-term changes. Techniques for overcoming the inhomogeneous vertical and spatial distribution of oceanographic measurements were presented. The analysis focused on the data of 1950 and onwards where more reliable instrumental observations exist. Comparisons with SeaDataNet V1.1 climatology (Simoncelli et al., 2015a, 2016, http://doi. org/10.12770/90ae7a06-8b08-4afe-83dd-ca92bc99f5c0) reveal a very good agreement. It was expected since both two climatologies use similar interpolation methodology. The atlas offers additional value-added decadal temperature and salinity distributions which already exist in the region from previous versions of Medar/Medatlas climatology, though with no error fields available. This is of particular importance.

There are still improvements to be implemented in future versions of the atlas, such as a three-dimensional analysis instead of stacking the two-dimensional horizontal levels together in order to take into account the vertical correlation of the parameters. This would reduce vertical inconsistencies that may remain in the results. In addition, the correction of the warm bias in the bathythermograph data, caused by instrumental errors, should also be addressed. However, it is anticipated that the approach followed here concerning the calibration of the analysis parameters will be followed by other groups in the future for the Mediterranean climate studies and other applications related with the long-term variability of the hydrological characteristics of the region and its climate change.

Another future improvement is the use of a dynamical constraint such as a real velocity field or an advection constraint based on topography that would allow anisotropies in the correlations to be included into the analysis. This atlas aims to contribute to existing available knowledge in the region and fill existing data gaps in space and time.

Author contributions. AI created the atlas, wrote the first version of the paper and prepared the figures. SS provided the MATLAB programs to compute the statistical indexes and plot them. JMB, SW, CT and AT reviewed the paper. CT and SW formatted the document in LaTeX.
Competing interests. The authors declare that they have no conflict of interest.

Disclaimer. It cannot be warranted that the atlas is free from errors or omissions. Correct and appropriate atlas interpretation and usage is solely the responsibility of data users.

Acknowledgements. The DIVA development has received funding from the European Union Sixth Framework Programme (FP6/2002-2006) under grant agreement no. 026212, SeaDataNet (http://www.seadatanet.org/, last access: 9 July 2018), the Seventh Framework Programme (FP7/2007-2013) under grant agreement no. 283607, SeaDataNet II, SeaDataCloud and EMODnet (http://www.emodnet.eu/, last access: 9 July 2018) (MARE/2008/03 - Lot 3 Chemistry - SI2.531432) from the http://ec.europa.eu/dgs/maritimeaffairs_fisheries/index_en.htm (last access: 9 July 2018) Directorate-General for Maritime Affairs and Fisheries.

Edited by: Giuseppe M. R. Manzella

Reviewed by: Alexey Mishonov and one anonymous referee

\section{References}

Beckers, J.-M., Barth, A., Troupin, C., and Alvera-Azcárate, A.: Some approximate and efficient methods to assess error fields in spatial gridding with DIVA (Data Interpolating Variational Analysis), J. Atmos. Ocean. Tech., 31, 515-530, https://doi.org/10.1175/JTECH-D-13-00130.1, 2014.

Bergamasco, A. and Malanotte-Rizzoli, P.: The circulation of the Mediterranean Sea: a historical review of experimental investigations, Advances in Oceanography and Limnology, 1, 11-28, https://doi.org/10.1080/19475721.2010.491656, 2010.

Béthoux, J.-P., Gentili, B., and Tailliez, D.: Warming and freshwater budget change in the Mediterranean since the 1940s, their possible relation to the greenhouse effect, Geophys. Res. Lett., 25, 1023-1026, https://doi.org/10.1029/98g100724, 1998.

Brankart, J.-M. and Brasseur, P.: Optimal analysis of In Situ Data in the Western Mediterranean Using Statistics and Cross-Validation, J. Atmos. Ocean. Tech., 13, 477-491, https://doi.org/10.1175/15200426(1996)013<0477:OAOISD>2.0.CO;2, 1996.

Brankart, J.-M. and Brasseur, P.: The general circulation in the Mediterranean Sea: a climatological approach, J. Marine Syst., 18, 41-70, https://doi.org/10.1016/S0924-7963(98)000050, 1998.

Brasseur, P., Beckers, J., Brankart, J., and Schoenauen, R.: Seasonal temperature and salinity fields in the Mediterranean Sea: Climatological analyses of a historical data set, Deep-Sea Res. Pt. I, 43, 159-192, https://doi.org/10.1016/0967-0637(96)00012-x, 1996.

Bretherton, F., Davis, R., and Fandry, C.: A technique for objective analysis and design of oceanic experiments applied to Mode73, Deep-Sea Res., 23, 559-582, https://doi.org/10.1016/00117471(76)90001-2, 1976.

Capet, A., Troupin, C., Carstensen, J., Grégoire, M., and Beckers, J.-M.: Untangling spatial and temporal trends in the variability of 
the Black Sea Cold Intermediate Layer and mixed Layer Depth using the DIVA detrending procedure, Ocean Dynam., 64, 315324, https://doi.org/10.1007/s10236-013-0683-4, 2014.

Gandin, L. S.: Objective analysis of meteorological fields. By L. S. Gandin. Translated from the Russian, Jerusalem (Israel Program for Scientific Translations), 1965, Q. J. Roy. Meteor. Soc., 92, 447-447, https://doi.org/10.1002/qj.49709239320, 1966.

Guibout, P.: Atlas Hydrologique de la Mediterranee, Shom, Ifremer, Paris, France, 1 Edn., 150 pp., 1987.

Hecht, A., Pinardi, N., and Robinson, A. R.: Currents, Water Masses, Eddies and Jets in the Mediterranean Levantine Basin, J. Phys. Oceanogr., 18, 1320-1353, https://doi.org/10.1175/15200485(1988)018<1320:CWMEAJ>2.0.CO;2, 1988.

Iona, A.: Mediterannean Sea-Temperature and Salinity Annual Climatology [Data set], Zenodo, https://doi.org/10.5281/zenodo.1146976, 2018a.

Iona, A.: Mediterannean Sea-Temperature and Salinity Seasonal Climatology for 57 running decades from 1950-1959 to 2006-2015 [Data set], Zenodo, https://doi.org/10.5281/zenodo.1146938, 2018b.

Iona, A.: Mediterannean Sea-Temperature and Salinity Seasonal Climatology [Data set], Zenodo, https://doi.org/10.5281/zenodo.1146953, 2018c.

Iona, A.: Mediterannean Sea-Temperature and Salinity Annual Climatology for 57 running decades from 1950-1959 to 2006-2015 [Data set], Zenodo, https://doi.org/10.5281/zenodo.1146957, 2018d.

Iona, A.: Mediterannean Sea-Temperature and Salinity Seasonal Climatology for six periods (1950-1959, 1960-1969, 19701979, 1980-1989, 1990-1999, 2000-2015) [Data set], Zenodo, https://doi.org/10.5281/zenodo.1146966, 2018e.

Iona, A.: Mediterannean Sea-Temperature and Salinity Annual Climatology for six periods (1950-1959, 1960-1969, 19701979, 1980-1989, 1990-1999, 2000-2015) [Data set], Zenodo, https://doi.org/10.5281/zenodo.1146970, $2018 \mathrm{f}$.

Iona, A.: Mediterannean Sea-Temperature and Salinity Monthly Climatology [Data set], Zenodo, https://doi.org/10.5281/zenodo.1146974, 2018g.

Klein, B., Roether, W., Manca, B. B., Bregant, D., Beitzel, V., Kovacevic, V., and Luchetta, A.: The large deep water transient in the Eastern Mediterranean, Deep-Sea Res. Pt. I, 46, 371-414, https://doi.org/10.1016/s0967-0637(98)00075-2, 1999.

Lascaratos, A., Roether, W., Nittis, K., and Klein, B.: Recent changes in deep water formation and spreading in the eastern Mediterranean Sea: a review, Prog. Oceanogr., 44, 5-36, https://doi.org/10.1016/s0079-6611(99)00019-1, 1999.

La Violette, P. E.: The Western Mediterranean Circulation Experiment (WMCE): Introduction, J. Geophys. Res., 95, 1511, https://doi.org/10.1029/jc095ic02p01511, 1990.

Levitus, S.: Climatological Atlas of the World Ocean, Tech. rep., NOAA Professional Paper 13, US. Government Printing Office: Washington, DC, 1982.

Locarnini, R. A., Mishonov, A. V., Antonov, J. I., Boyer, T. P., Garcia, H. E., Baranova, O. K., Zweng, M. M., Paver, C. R., Reagan, J. R., Johnson, D. R., Hamilton, M., and Seido, D.: World Ocean Atlas 2013, Volume 1: Temperature, in: NOAA Atlas NESDIS, edited by: Levitus, S. and Mishonov A., 73, 40 pp., NOAA, available at: http://data.nodc.noaa.gov/woa/ WOA13/DOC/woa13_vol1.pdf (last access: 9 July 2018), 2013.
Lozier, M. S., Owens, W. B., and Curry, R. G.: The climatology of the North Atlantic, Prog. Oceanogr., 36, 1-44, https://doi.org/10.1016/0079-6611(95)00013-5, 1995.

Malanotte-Rizzoli, P. and Hecht, A.: Large-scale properties of the eastern mediterranean: a rewiew, Oceanol. Acta, 11, 323-335, 1988.

Malanotte-Rizzoli, P., Manca, B. B., d'Alcala, M. R., Theocharis, A., Brenner, S., Budillon, G., and Ozsoy, E.: The Eastern Mediterranean in the 80 s and in the 90s: the big transition in the intermediate and deep circulations, Dynam. Atmos. Oceans, 29, 365-395, https://doi.org/10.1016/s0377-0265(99)00011-1, 1999.

Manca, B., Burca, M., Giorgetti, A., Coatanoan, C., Garcia, M.-J., and Iona, A.: Physical and biochemical averaged vertical profiles in the Mediterranean regions: an important tool to trace the climatology of water masses and to validate incoming data from operational oceanography, J. Marine Syst., 48, 83-116, https://doi.org/10.1016/j.jmarsys.2003.11.025, 2004.

Manzella, G. M. R. and Gambetta, M.: Implementation of real-time quality control procedures by means of a probabilistic estimate of seawater temperature and its temporal evolution, J. Atmos. Ocean. Tech., 30, 609-625, https://doi.org/10.1175/JTECH-D11-00218.1, 2013.

MEDAR Group: MEDATLAS/2002 database, Mediterranean and Black Sea database of temperature salinity and bio-chemical parameters, Climatological Atlas, Tech. rep., Ifremer, 4 Cdroms, 2002.

Millot, C.: Circulation in the Western Mediterranean Sea, Oceanol. Acta, 10, 143-148, 1987.

Millot, C.: Mesoscale and seasonal variabilities of the circulation in the western Mediterranean, Dynam. Atmos. Oceans, 15, 179214, https://doi.org/10.1016/0377-0265(91)90020-G, 1991.

Millot, C.: Circulation in the Western Mediterranean Sea, J. Marine Syst., 20, 423-442, https://doi.org/10.1016/S09247963(98)00078-5, 1999.

Ovchinnikov, I.: Circulation in the surface and intermediate layers of the mediterranean, Oceanology, 6, 49-59, 1966.

Picco, P.: Climatological Atlas of the Western Mediterranean, Tech. rep., ENEA Santa Teresa Centre, La Spezia, Italy, 224 pp., 1990.

Rahmstorf, S.: Influence of mediterranean outflow on climate, EOS T. Am. Geophys. Un., 79, 281-281, https://doi.org/10.1029/98eo00208, 1998.

Reiniger, R. and Ross, C.: A method of interpolation with application to oceanographic data, Deep-Sea Res., 15, 185-193, https://doi.org/10.1016/0011-7471(68)90040-5, 1968.

Rixen, M., Beckers, J.-M., Brankart, J.-M., and Brasseur, P.: A numerically efficient data analysis method with error map generation, Ocean Modell., 2, 45-60, https://doi.org/10.1016/S14635003(00)00009-3, 2000.

Rixen, M., Beckers, J.-M., and Allen, J.: Diagnosis of vertical velocities with the QG Omega equation: a relocation method to obtain pseudo-synoptic data sets, Deep-Sea Res. Pt. I, 48, 1347-1373, https://doi.org/10.1016/S0967-0637(00)00085-6, 2001.

Rixen, M., Beckers, J.-M., Levitus, S., Antonov, J., Boyer, T., Maillard, C., Fichaut, M., Balopoulos, E., Iona, S., Dooley, H., Garcia, M.-J., Manca, B., Giorgetti, A., Manzella, G., Mikhailov, N., Pinardi, N., Zavatarelli, M., and the Medar Consortium: The Western Mediterranean Deep Water: a proxy 
for global climate change, Geophys. Res. Lett., 32, L12608, https://doi.org/10.1029/2005GL022702, 2005.

Robinson, A., Leslie, W., Theocharis, A., and Lascaratos, A.: Mediterranean Sea Circulation, Encyclopedia of Ocean Sciences, 1689-1705, https://doi.org/10.1006/rwos.2001.0376, 2001.

Roether, W., Manca, B. B., Klein, B., Bregant, D., Georgopoulos, D., Beitzel, V., Kovacevic, V., and Luchetta, A.: Recent Changes in Eastern Mediterranean Deep Waters, Science, 271, 333-335, https://doi.org/10.1126/science.271.5247.333, 1996.

Schlitzer, R.: Interactive analysis and visualization of geoscience data with Ocean Data View, Comput. Geosci., 28, 1211-1218, https://doi.org/10.1016/S0098-3004(02)00040-7, 2002.

Schröder, K., Gasparini, G. P., Tangherlini, M., and Astraldi, M.: Deep and intermediate water in the western Mediterranean under the influence of the Eastern Mediterranean Transient, Geophys. Res. Lett., 33, https://doi.org/10.1029/2006gl027121, 2006.

Schroeder, K., Chiggiato, J., Bryden, H. L., Borghini, M., and Ben Ismail, S.: Abrupt climate shift in the Western Mediterranean Sea, Scientific Reports, 6, 23009, https://doi.org/10.1038/srep23009, 2016.

SeaDataNet Group: Data Quality Control Procedures, Tech. Rep. Version 2.0, SeaDataNet consortium, availabel at: https://www.seadatanet.org/content/download/596/3118/file/ SeaDataNet_QC_procedures_V2_(May_2010).pdf?version=1, (last access: 9 July 2018), 2010.

Simoncelli, S., Tonani, M., Grandi, A., Coatanoan, C., Myroshnychenko, V., Sagen, H., Back, O., Scory, S., Schlitzer, R., and Fichaut, M.: First Release of the SeaDataNet Aggregated Data Sets Products, WP10 Second Year Report - DELIVERABLE D10.2, https://doi.org/10.13155/49827, 2014.

Simoncelli, S., Coatanoan, C., Myroshnychenko, V., Sagen, H., Back, O., Scory, S., Grandi, A., Barth, A., and Fichaut, M.: SeaDataNet, First Release of Regional Climatologies, WP10 Third Year Report - DELIVERABLE D10.3, available at: https://doi.org/10.13155/50381, 2015a.

Simoncelli, S., Coatanoan, C., Myroshnychenko, V., Sagen, H., Back, O., Scory, S., Grandi, A., Schlitzer, R., and Fichaut, M.: Second release of the SeaDataNet aggregated data sets products, WP10 Fourth Year Report - DELIVERABLE D10.4, https://doi.org/10.13155/50382, 2015 b.

Simoncelli, S., Grandi, A., and Iona, S.: New Mediterranean Sea climatologies, Bollettino di Geofisica, Vol. 57 - Supplement, 2016, 252 pp., available at: https://imdis.seadatanet.org/ Previous-editions/IMDIS-2016/Proceedings (last access: 9 July 2018), 2016.
Troupin, C., Machín, F., Ouberdous, M., Sirjacobs, D., Barth, A., and Beckers, J.-M.: High-resolution Climatology of the North-East Atlantic using Data-Interpolating Variational Analysis (Diva), J. Geophys. Res., 115, C08005, https://doi.org/10.1029/2009JC005512, 2010.

Troupin, C., Sirjacobs, D., Rixen, M., Brasseur, P., Brankart, J.M., Barth, A., Alvera-Azcárate, A., Capet, A., Ouberdous, M., Lenartz, F., Toussaint, M.-E., and Beckers, J.-M.: Generation of analysis and consistent error fields using the Data Interpolating Variational Analysis (Diva), Ocean Modell., 52-53, 90-101, https://doi.org/10.1016/j.ocemod.2012.05.002, 2012.

Troupin, C., Watelet, S., Barth, A., and Beckers, J.-M.: Diva-UserGuide: v1.0 (Version v1.0). Zenodo., Tech. rep., GeoHydrodynamics and Environment Research, University of Liège, Liège, Belgium, https://doi.org/10.5281/zenodo.836723, 2017.

Watelet, S., Ouberdous, M., Troupin, C., Barth, A., and Beckers, J.M.: DIVA Version 4.6.11, Tech. rep., GeoHydrodynamics and Environment Research, University of Liège, Liège, Belgium, https://doi.org/10.5281/zenodo.400970, 2015a.

Watelet, S., Ouberdous, M., Troupin, C., Barth, A., and Beckers, J.-M.: DIVA Version 4.6.9, Tech. rep., GeoHydrodynamics and Environment Research, University of Liège, Liège, Belgium, https://doi.org/10.5281/zenodo.400968, 2015b.

Watelet, S., Troupin, C., Beckers, J.-M., Barth, A., and Ouberdous, M.: DIVA Version 4.7.1, Tech. rep., GeoHydrodynamics and Environment Research, University of Liège, Liège, Belgium, https://doi.org/10.5281/zenodo.836727, 2017.

Wijffels, S. E., Willis, J., Domingues, C. M., Barker, P., White, N. J., Gronell, A., Ridgway, K., and Church, J. A.: Changing Expendable Bathythermograph Fall Rates and Their Impact on Estimates of Thermosteric Sea Level Rise, J. Climate, 21, 56575672, https://doi.org/10.1175/2008jcli2290.1, 2008.

Zweng, M., Reagan, J., Antonov, J., Locarnini, R., Mishonov, A., Boyer, T., Garcia, H., Baranova, O., Johnson, D., Seidov, D., and Biddle, M.: World Ocean Atlas 2013, Volume 2: Salinity, in: NOAA Atlas NESDIS, edited by: Levitus, S. and Mishonov, A., 74, 39 pp., NOAA, available at: http://data.nodc.noaa.gov/woa/ WOA13/DOC/woa13_vol2.pdf (last access: 9 July 2018), 2013. 